\title{
The role of Intermediate Respiratory Care Units in preventing ICU collapse during the COVID pandemic.
}

Sarah Heili ( $\sim$ sheili@fjd.es )

Hospital Universitario Fundacion Jimenez Diaz https://orcid.org/0000-0003-4901-6487

María del Pilar Carballosa de Miguel

Hospital Universitario Fundacion Jimenez Diaz

Alba Naya Prieto

Hospital Universitario Fundacion Jimenez Diaz

Itziar Fernández Ormaechea

Hospital Universitario Fundacion Jimenez Diaz

Farah Ezzine de blas

Hospital Universitario Fundacion Jimenez Diaz

Pablo López Yeste

Hospital Universitario Fundacion Jimenez Diaz

Francisco Jos Laso del Hierro

Hospital Universitario Fundacion Jimenez Diaz

Ainhoa Izquierdo Pérez

Hospital Universitario Fundacion Jimenez Diaz

Marwan Mohamed Choukri

Hospital Universitario Fundacion Jimenez Diaz

Herminia Ortiz Mayoral

Hospital Universitario Fundacion Jimenez Diaz

Abdulkader El Hachem Debek

Hospital Universitario Fundacion Jimenez Diaz

Andrés Giménez Velando

Hospital Universitario Fundacion Jimenez Diaz

Marcel José Rodriguez Guzmán

Hospital Universitario Fundacion Jimenez Diaz

Elena Cabezas Pastor

Hospital Universitario Fundacion Jimenez Diaz

Pablo Minguez

Hospital Universitario Fundacion Jimenez Diaz

Ignacio Mahillo Fernández 
Hospital Universitario Fundacion Jimenez Diaz

\section{Antonio Herrero González}

Hospital Universitario Fundacion Jimenez Diaz

\section{Lorena De La Fuente}

Hospital Universitario Fundacion Jimenez Diaz

\section{Luis Jiménez Hiscock}

Hospital Universitario HM Sanchinarro

\section{Sandra Pelícano Vizuete}

Hospital Universitario Fundacion Jimenez Diaz

\section{Rebeca Armenta Fernández}

Hospital Universitario Fundacion Jimenez Diaz

\section{María José Checa Venegas}

Hospital Universitario Fundacion Jimenez Diaz

\section{Germán Peces-Barba Romero}

Hospital Universitario Fundacion Jimenez Diaz

\section{Research}

Keywords: SARS-CoV-2 Pandemic, Neural Network, Artificial Intelligence, CPAP, NIMV, High Flow Oxygen, Cyclosporine, Tocilizumab, Corticosteroids

Posted Date: August 17th, 2020

DOI: https://doi.org/10.21203/rs.3.rs-52228/v1

License: (c) (i) This work is licensed under a Creative Commons Attribution 4.0 International License.

Read Full License 


\section{The role of Intermediate Respiratory Care Units in preventing ICU collapse during the COVID pandemic.}

Sarah Heili-Frades $\mathrm{MD}^{1}{ }^{*}$, María del Pilar Carballosa de Miguel MD1, Alba Naya Prieto MD1, Itziar Fernández Ormaechea MD1, Farah Ezzine de Blas MD1, Pablo Lopez Yeste MD2 , Francisco Jos Laso Del Hierro MD2 , Ainhoa Izquierdo Perez MD2, Marwan Mohamed Choukri MD2, Herminia Ortiz Mayoral MD2, Abdulkader El Hachem Debek $M D^{2}$, Andres Gimenez Velando MD2 , Marcel Jose Rodriguez Guzman MD2, Elena Cabezas Pastor2, Pablo Minguez PHD³, Ignacio Mahillo Fernández PHD4, Antonio Herrero González ${ }^{5}$, Lorena de la Fuente PHD ${ }^{6}$, Luis Jiménez Hiscock MD7, Sandra Pelícano Vizuete ${ }^{8}$, Rebeca Armenta ${ }^{8}$, María José Checa Venegas ${ }^{8}$, and Germán Peces-Barba Romero MD PHD1.

1 Intermediate Respiratory Care Unit, IIS-Fundación Jiménez Díaz Quirón Salud, Madrid, CIBER de enfermedades respiratorias (CIBERES), REVA Network. Avda Reyes Católicos 2, 28040 , Madrid, Spain.

2 Pulmonology Department. Fundación Jiménez Díaz Quirón Salud, Madrid, Avda Reyes Católicos 2, 28040 , Madrid, Spain.

3 Genetics and Genomics Department, IIS-Fundación Jiménez Díaz-Universidad Autonoma de Madrid (IIS-FJD, UAM), Center for Biomedical Network Research on Rare Diseases (CIBERER), ISCIII. Avda Reyes Cat.licos 2, 28040, Madrid, Spain.

4 Department of Biostatistics and Epidemiology, IIS- Fundación Jiménez Díaz-Universidad Autonoma de Madrid (IISFJD, UAM), Madrid, Spain. Avda Reyes Cat.licos 2, 28040, Madrid, Spain.

5 Data Analytics Director, Department of Big Data analytics, IIS- Fundación Jiménez Díaz Universidad Autonoma de Madrid (IIS-FJD, UAM). Avda Reyes Cat.licos 2, 28040, Madrid,

Spain.

6 Bioinformatics Unit, IIS- Fundación Jiménez Díaz -Universidad Autonoma de Madrid (IIS-FJD, UAM), Avda Reyes Cat.licos 2, 28040, Madrid, Spain.

7 Thoracic Surgery Dept. Sanchinarro University Hospital, HM Hospitals Group, Calle de Oña, 10, 28050 Madrid, Spain

8 Nurses's Directors. Intermediate Respiratory Care Unit, IIS-Fundación Jiménez Díaz Quirón Salud, Madrid. REVA Network. Avda Reyes Católicos 2, 28040 , Madrid, Spain.

\section{Corresponding Author:}

*Sarah Heili Frades

Intermediate Respiratory Care Unit, IIS-Fundación Jiménez Díaz Quirón Salud, Madrid, CIBERES, REVA Network.

Avda. Reyes Católicos, 2, 28040 Madrid

e-mail SHeili@fjd.es

+34609324922 


\section{ABSTRACT}

Introduction: There is limited information describing features and outcomes of patients requiring Intermediate Respiratory Care Unit (IRCU) hospitalization for COVID19 disease and as of yet, no mechanical or medical treatments have clearly demonstrated efficacy in IRCU.

Methods: Demographics and clinical variables on admission, as well as medical and mechanical therapeutic interventions, were extracted from Electronic Clinical Records in 274 SARS-CoV-2 infected patients attending a third level hospital IRCU. Using multivariate logistic regression analysis, variables that best discriminated mortality were obtained. Principal components analysis and a neural network (NN) algorithm were applied.

Results: In relation to respiratory support, high-flow oxygen therapy and weaning procedures were associated with survival as were CPAP and non-invasive ventilation with low levels of support among the most severely affected. The IRCU achieved a survival rate of $87.6 \%$, avoided 178 ICU admissions, successfully referred $35 \%$ to the ICU, and of these, $94 \%$ later survived the weaning phase. Higher mortality incidence was associated with cardiac and respiratory diseases and fever, heart rhythm and blood pressure disturbances. Following analysis of specific therapeutic options Corticoids and Anticoagulants were associated with better outcomes.

Conclusions: The IRCU prevented the collapse of the ICU, allowed for recovered ICU patients to be quickly released from their unit, thus freeing up critical care beds and permitting them to function more effectively and in terms of mortality, achieved good results, that did not worsen due to a possible delay in intubation. In addition, we have generated an open-access NN capable of identifying severity predictors of SARS-CoV-2.

\section{Word Count For The Abstract: 250, Word Count For The Text: 3537}

Key Words: SARS-CoV-2 Pandemic; Neural Network; Artificial Intelligence; CPAP; NIMV; High Flow Oxygen; Cyclosporine; Tocilizumab; Corticosteroids 


\section{Introduction}

During the current pandemic, the Intermediate Respiratory Care Unit (IRCU) dealt directly with patients suffering from very severe respiratory failure due to viral pneumonia caused by SARS-

CoV-2. Four lines of respiratory therapies were applied: Continuous Positive Airway Pressure (CPAP), Non Invasive Mechanical Ventilation (NIMV) and High Flow Oxygen (HFO) in the acute phase and Invasive Mechanical Ventilation (IMV) during weaning.

We describe the IRCU's experience and results, which was able to quadruple it's capacity in less than a week, while being attended by three 24 -hour on-duty pulmonologists and supported by six more physicians from other specialties. Regulations and recommendations established through national consensus were followed when treating this entity 1

Regarding HFO systems, air mixing was quickly eliminated due to hypoxemia. But strict control of oxygen partial pressure was necessary to avoid hyperoxia ${ }^{2}$ and to timely identify the existence of refractory shunts that would not respond to oxygen therapy33. New procedures were acquired from the ICU to help solve such extreme hypoxia, such as the prone position ${ }^{4}$ combined with HFO therapy or NIMV. Lower pressurization rates and pressure supports were used to avoid overventilation and volutrauma5injury (VILI).

Throughout this pandemic, weaning of some patients during the recovery phase has overlapped the hyperacute peak flow phase of acutely ill patients, and the IRCU had to quickly adapt to successfully face these two synchronous situations, implementing two different protocols of action at the same time, which required a high level of organization and excess demand upon medical and nursing staff.

The object of this study is to analyze mortality using direct statistical analysis based on logistic regression and predictive NN analysis. This article also illustrates patients' flow between the ICU and our highly specialized IRCU with more than 20 years of experience $e^{6,7,8}$. 


\section{MATERIAL AND METHODS}

\section{Study Population}

A total of 274 patients from January 1 st 2020 to May 5th 2020 admitted to a third-level hospital IRCU were included. All patients had confirmed SARS-CoV-2 infection by a positive result upon polymerase chain reaction testing. The local clinical practice guide (detailed in Table 1 supplemental) was followed which includes the admission criteria in IRCU or ICU. De-identified medical records were confidentially collected from Microsoft Sql Integration Services (SSIS) reporting database and analyzed using $R$ version 3.5.2 ( $R$ Project for Statistical Computing; $R$ Foundation). Approval from the Institutional Ethics Committee was obtained. All methods were carried out in accordance with relevant guidelines and regulations.

\section{Data Collection and baseline variables included in the study}

Demographics, baseline comorbidities, vital signs, use of treatments, either mechanical or medical, and outcomes were extracted from clinical charts and manually revised.

\section{Missing Data Imputation}

Patients and parameters with a high percentage (>50\%) of missing values were excluded from the analysis. In the remaining patients, missing data was imputed using $\mathrm{KNN}$ method $(\mathrm{K}=5)$.

\section{Neural Network And Data Re-Sampling}

The neural network (NN) model was built using the caret $R$ package (https://CRAN.Rproject.org/package=caret). We used the "nnet" method, and implemented an automatic selection of: i) the optimal number of units per hidden layer (1 to 5 ), and ii) the optimal value for the regularization parameter to avoid over-fitting ( 0.1 to 0.5 in increments of 0.1 units). We used the "twoClassSummary" method to compute sensitivity, specificity and the area under the ROC 
curve. This NN algorithm was performed 10 times over a matrix of re-sampled patients. Resampled matrices were composed of patients with severe status (outcome $=1$ ) and a random selection of the same number of patients with less severe status (outcome $=0$ ). For each resampled matrix, we performed a 10 -fold cross validation where $90 \%$ of patients we randomly used as the training dataset and the remaining (10\%) as the testing dataset. A total of $100 \mathrm{NN}$ models were performed and a ROC curve was calculated for the set of predictions and real values using 10-fold cross-validation. The final AUC, accuracy, sensitivity and specificity were calculated as the mean of the $100 \mathrm{NN}$ models performed in total. Our R script is available at: https://github.com/pminguez/MachineLearning4UnbalancedData/blob/master/nn4covid19.R

\section{Principal Component Analysis}

Principal component analysis (PCA) was performed on the matrices with missing data imputation, centered and scaled, using the prcomp and factoextra $\mathrm{R}$ libraries. Elipses represent $95 \%$ of the data. PCA analyses were performed over the same scenarios chosen to perform the NN.

\section{Fisher exact test analysis}

For binary type of variables, which included comorbidities, treatments and gender, odds ratios for each of the two severity classes in each comparison were calculated, contingency $2 \times 2$ tables were obtained and significance was calculated with 2-tailed Fisher test. P values were adjusted using FDR and adjusted $p$ values $<0.05$ were taken as significant. Graphics were built sorting variables by relative odds ratios (1/odds ratio when $<1$ ).

\section{Wilcoxon test analysis}

For non-binary variables comprising vital signs, a non-parametric Wilcoxon rank sum test was performed over the set of values of each variable for the two severity states. P-values were 
adjusted by FDR and FDR<0.05 were considered as significant. Means of the two sets of values for each variable was calculated to assign a direction of the test.

\section{Logistic Regression Classification based on comorbilities, vital signs and drug consumption}

First, the univariate logistic regression models were obtained. Then, the best multivariable model was sought. For this, all possible models were adjusted, and the one with the lowest AIC value (Akaike Criterion) was chosen. Finally, the goodness of fit of the model was assessed (Hosmer and Lemeshow Test), and the ROC curve was obtained using the Leave One Out (LOO) crossvalidation technique.

\section{Analysis of the effect of mechanical devices on survival in this cohort of patients}

Fisher's exact test was performed to investigate the association between the type of respiratory support and mortality. To compare the parameters used with the different techniques and their association with mortality, the student's t test was used. In all cases it was considered that there was statistical significance when $p<0.05$. We applied our NN based algorithm to detect treatments predicting success or failure. The Fisher test was applied to binary data while Wilcoxon was used with continuous data. 


\section{Results}

\section{Cohort Description}

Supplementary Figure 1 shows epidemiologic data, drugs used and comorbidities of the patients, while Figure 1 describes the dataset, with a global mortality rate of $12,4 \%, 178$ ICU admissions were avoided, $35 \%$ of IRCU patients required transfer to the ICU and of these, $96 \%$ of them later survived at weaning. Of the patients included, $20.8 \%$ were $<50$ years, $44.5 \%$ were between 50 and 70 and $34.3 \%$ were over 70 years old.

Mortality increased with age, reaching $32 \%$ in patients older than 70 years (Figure 1B). A day-today report of deaths (Figure 1C) and fortnite mortality (Figure 1D-E) illustrate a higher mortality rate at the beginning of the pandemic. Mortality reached it's maximum in early March amongst the elderly, and then progressively decreased, being clearly contained by early April. Supplementary Figure 2 presents the Helmet cohort, showing Comorbidities, Biomarkers and global and Helmet vital signs.

\section{Comorbidities associated with worst prognosis}

We performed PCA and NN analyses over the 274 patients, classifying them into two states deceased vs. alive or transferred to ICU - at the time of data collection. Figure 2A shows principal component (PC or dimension 1) against PC2. Cardiovascular affections and respiratory disorders were the conditions which most contributed to separation between states. Odds ratios of the different comorbidities further revealed that seven disease families were associated with fatal outcomes without enrichment. Figure 2 B show results for Ages between 50-70 years (123 patients) where tobacco consumption, cardiac and respiratory disease were most relevant, while for those older than 70 years (94 patients) Figure 2C respiratory and oncological disease seemed to be the most important comorbidities related to death. For the most severe patients 
$(n=130)$ transferred to ICU or dead, Hypertension, cardiac, respiratory or oncological disease show a trend contributing to separation between states with an AUC=0.66 (Supplementary Figure 3).

Univariate and multivariate regression analysis confirms the results obtained by the $\mathrm{NN}$ in the overall cohort (Table 1) and in the more severe patients (Table 2). The LOO-CV AUC for the logistic model was $0.73(0.64,1)$ for the overall cohort and the Hosmer-Lemeshow test reached $p$ $=1$. The LOO-CV AUC for the logistic model in the more severe was $0.53(0.68,0,62)$ and the Hosmer-Lemeshow test reached $p=1$ for the more severe patients (Supplementary Figure $4 \mathrm{~A}$ and B). We note that all comorbidities were collected from electronic medical records without data associated with them in relation to the severity of the disease or the syndromic type.

\section{Risk prediction by vital signs and their cut-off values}

In relation to abnormal vital signs in the Emergency Department, heart rate and temperature were found to be the variables which best discriminated between deceased patients and survivors, according to PCA and NN analysis for all patients (Figure $3 A$ ). The NN was able to classify patients with an AUC $=0.68$, achieving a value of 0.83 when the classification was made in the 50 70 year range, where temperature, heart rate and systolic blood pressure (Figure 3B) were selected. Similar results were obtained in patients $>70$ years (Figure $3 \mathrm{C}$ ). Results between deceased and ICU-admitted patients show relevance of bradycardia, hypothermia and arterial blood pressure (Supplementary Figure 5).

Univariate and multivariate regression analysis confirmed the results obtained by the NN with oxygen saturation being significant in the overall cohort (Table 3), as in more severe patients (Table 4). The LOO-CV AUC for the logistic model was $0.76(0.76,0,69)$ for the overall cohort and the Hosmer-Lemeshow test reached $p=0,773$. The LOO-CV AUC for the logistic model in 
the more severe was $0.83(0.88,0,67)$ and the Hosmer-Lemeshow test reached $p=0,114$ for the more severe patients, (Supplementary Figure 6 A and B).

\section{Therapeutic modalities and patient survival}

\section{Medical Treatment}

In the 50-70 year range, drugs associated with survival were Corticoids, Chloroquine, Lopinavir and Cyclosporine (Figure 4A). Regarding those $>70$ years (Figure 4B), Corticoids, Betaferon and Anticoagulants show a trend associated with survival. We further explored the effect of drugs on survival in the most severe group of patients. Interestingly, PCA showed a clear separation between these categories and revealed a positive contribution of all specific drugs to survival. And the NN in this cohort show (Figure $4 \mathrm{C}$ ), with an $\mathrm{AUC}=0.88$, that Corticoids, Enoxaparin, Acetylcisteine, Beta interferon, Tocilizumab, Lopinavir, and Cyclosporine were the compounds with greater capacity to classify patients. Enrichment analysis showed the benefit of these drugs, with high odds ratios and FDR $<0.05$, along with Betaferon. NN in severe patients older than 70 years attain an AUC of 0,83 with similar results and a contribution of Anakinra to survival without enrichment (Supplementary Figure 7).

It is important to highlight that both univariate and multivariate regression analysis confirm the results obtained by the NN in the overall cohort (Table 5) and in the more severe patients (Table 6). The LOO-CV AUC for the logistic model was $0.65(0.82,0,76)$ for the overall cohort and the Hosmer-Lemeshow test reached $p=1$. The LOO-CV AUC for the logistic model in the more severe was $0.91(0.79,0,92)$ and the Hosmer-Lemeshow test reached $p=0,998$ for the more severe patients (Supplementary Figure $8 \mathrm{~A}$ and B). 


\section{$\underline{\text { Respiratory Support Therapies }}$}

Regarding respiratory support, Figure 5A shows the use of support techniques, including Helmet, which was only used in $2.18 \%$ of the subjects. NIMV was used in $13.41 \%$, CPAP in $23.7 \%$, HFO in $40.5 \%$ and IMV, only for weaning, in $13.5 \%$.. The rest of the patients were on Oxygen alone either by nasal cannula or mask. In general, given the high minute volumes of the patients, HFO was chosen as the initial therapy. When hypoxemia was refractory, a CPAP test was performed and maintained if recruitment improved hypoxemia. In case of a history of COPD, hypercapnia or previous use, NIMV with low levels of support pressure was used. Helmet was relegated to extreme situations. There is an association between the type of respiratory support and mortality. Figure 5 B shows the parameters used. Pressure Support and PEEP levels refer to NIMV through Helmet or full-face mask, CPAP levels refer to equipment capable of administering this mode of ventilation except Helmet. We must consider that two devices were used with the HFO: the Optiflow ${ }^{\top M}$ system (Fisher \& Payckel Healthcare) where the air and oxygen flow was selected separately and Precision Flow (Vapotherm Inc) in which the total flow and Fi02 were fixed. The Student's t-test Figure $\mathbf{5} \mathbf{C}$ shows that the choice of parameters is related to survival. NN Figure 6A show that HFO and the tracheotomy weaning procedure that incorporated the use of a hemicannula with an AUC of 0.97 are associated with survival. In the cohort of severe patients older than 70 years Figure 6B, all techniques improved survival, being CPAP especially robust once its programming value is included and weaning. NIMV and HFO were also associated with survival and the only technique in this group of patients associated with mortality is Helmet ventilation, although it was only used in 6 patients. Oxygen alone, either through nasal cannula or mask weren't related to survival. 


\section{Discussion}

The study demonstrates that IRCU admission did not worsen mortality and limited the demand for ICU resources. The IRCU prevented a collapse of the ICU, allowed it to quickly release patients so as to effectively return to normal, and achieved, considering the severity of lung injury, good results in terms of mortality, which did not increase because of a possible delay in intubation. Also, the present study illustrates the performance of a NN capable of identifying and classifying mortality predictors in SARS-CoV-2 infected patients that can be used in future mono or multicenter studies. Different statistical approaches were used in the treatment of data. The principal component analysis shows a photograph of the distribution of the variables, the logistic regression extracts those associated with survival, and the neural network selects those associated with survival with the greatest predictive power in a model designed to achieve selflearning and improve predictive capacity when increasing the size of the sample.

In the cohort, male subjects, as previously described ${ }^{9}$, were more frequently affected. Among those admitted, $12.4 \%$ died, considering survival (52.5\%) and the possibility of transfer to the ICU $(35 \%)$ as success. Normally, transfer to the ICU is a criterion of IRCU failure, but in this pandemic keeping the patient alive and well oxygenated until achieving an ICU bed was decisive. In fact, the patients referred to this unit returned for the most part to wean ( $80 \%)$ and $94 \%$ survived. $6 \%$ died in the ICU, so we can conclude that intubation was not ultimately delayed. In our ICU, all beds were finally able to dedicate to invasive support since the ICRU absorbed the non-invasive support in its entirety. If this had not been the case, it would have collapsed since the number of subjects treated at the UCRI far exceeded the available ICU beds. The reduction in mortality by early April may be likely due to better access to the ICU (Figure 1E), the use of weaning procedures without mortality, better organization, better use of the therapeutic guide and perhaps drugs associated with survival. 
Regarding comorbidities, we detect that underlying diseases, including hypertension, respiratory, cardiovascular and oncological disease, may be risk factors for severe patients compared with non-severe patients ${ }^{10,11}$. In general cohorts ${ }^{12,13,14}$, the discriminating risk factors are hypertension, diabetes and neurological disorders. Although renal dysfunction seems to be protective according to the analysis of neural networks, the logistic regression rules it out (Tables 1 and 2).

In regard to vital signs, arterial blood pressure alterations, heart rate and temperature are better predictors of poor prognosis, as previously docummented ${ }^{13,15}$. The multivariate regression model selects hypoxemia and hyperoxia also. This underlines the importance of containing extreme saturations in this type of patient?2.

Regarding treatment, the institution was guided by a unified protocol. In almost all cases either with NN or Logistic Regression, with the limitations of this type of study, it is possible to glimpse a signal in favor of steroids, and anticoagulants were associated with survival, as indicated by other authors $15,16,17,18,19,20$, and among the youngest and most seriously ill, other compounds such as Lopinavir, Tocilizumab and Cyclosporine stood out, which has already been described in broader cohorts considering cytokine storm syndrome and immunosuppression ${ }^{15,21}$. Corticosteroids are controversial in COVID-19 pneumonia in accordance with current WHO guidance ${ }^{22}$. However, in agreement with previous observations ${ }^{23}$, we found that their combination with other drugs was consistently associated to a higher survival. Tocilizumab is currently undergoing a clinical trial, but data from a pilot study ${ }^{24}$ suggests that it could have a beneficial effect. In severe cases, the role of Acetylcysteine stands out, probably improving the dense secretions and possibly having an antioxidant effect ${ }^{25}$. The use of Cyclosporine $A$ has been recently discussed ${ }^{26}$. Our institution set up a randomized clinical trial assessing the efficacy of Cyclosporine as an add-on therapy to standard of care, which is now ongoing27. All these conclusions regarding the advantages of one or the other treatments must be confirmed in randomized clinical trials in order to validate them. 
During the pandemic, mortality in the IRCU has doubled its usual annual rate of around $6 \%$ while attending approximately 250 patients per year ${ }^{8}$. During this current crisis, the IRCU treated nearly 300 patients during a month and a half period.

With respect to Helmet, it was only used in 6 patients with a mortality of $100 \%$. This was probably related to the decision of relegating this mask to the final stage of refractory extreme hypoxia. In Supplementary Figure 2, there are evident severity features of these patients compared to the general cohort. However, during this pandemic Helmet has been recommended as the first choice interface ${ }^{1}$. It has been described to improve the prognosis in patients with ARDS ${ }^{28}$ minimize aerosolization and dispersion of particles from the respiratory tract ${ }^{29}$, as well as decrease the incidence of complications usually associated with other masks $30,31,32$. In the institution, personnel have already been trained for a possible future wave in which this technique will be in the front line.

HFO has shown remarkable superiority in the cohort. In randomized controlled trials ${ }^{33}$ HFO has been shown to improve survival in non-intubated patients by comparison with simple oxygen therapy or noninvasive ventilation. In this cohort, a poor evolution is clearly seen in subjects treated with 02 only $\left(\mathrm{O}_{2}\right.$ Mask or reservoir bag) Figure $6 \mathrm{~A}$. As it has been described ${ }^{34}, 35$, it reduces the ventilatory demand, the severity of dyspnea and the respiratory rate. In consequence it decreases risk of (P-SILI) ${ }^{54}$.

Regarding CPAP, the current data shows an association with survival in the most severe patients. In COVID-19 patients, the recommendation of NIMV use is still being debated ${ }^{36}$. It is included in the $\mathrm{WHO}^{37}$, the Italian Thoracic Society ${ }^{38}$ and the Respiratory Care Committee of the Chinese Thoracic Society ${ }^{39}$ recommendations, but it is advised against in the European Society of Intensive Care Medicine and the Society of Critical Care Medicine ${ }^{40}$. In a recent French retrospective observational study, the use of CPAP was associated with lower intubation rate, 
particularly in patients with a do-not-intubate (DNI) decision ${ }^{41}$. Some studies even begin to recommend non-invasive support due to excess mortality from invasive ventilation ${ }^{42}$. Increased respiratory drive observed in these patients often conduced to spontaneous tidal volumes above $9 \mathrm{ml} / \mathrm{kg}$, which was associated with mortality ${ }^{43}$, which in turn lead to a need to reduce pressure support and even restrict its use to COPD patients or ventilatory failure ${ }^{1}$. The reduction of breathing rate and work of breathing after the introduction of NIMV, in order to avoid patient self-inflicted lung injury (P-SILI) $44,45,46$, was closely monitored, and determined if sedation/neuromuscular blockade and invasive mechanical ventilation was needed.

Remarkably higher lung compliance in COVID-19 patients was observed, distinguishing it from other forms of ARDS47. Lower support pressure levels were found to be protective, probably in relation to lower minute volume ventilation in the context of the aforementioned P-SILI.

Regarding weaning and decannulation of tracheostomized patients, the IRCU follows a specific protocol48, in which a tracheal hemi-cannula is placed in most patients. Both extubated and tracheostomized patients were admitted following ICU discharge, allowing to quickly freeing up ICU beds and resources. All of these patients survived. Open tracheostomy was performed in all cases following COVID-19 recommendations ${ }^{49}$. Delirium was a limitation during weaning ${ }^{50}$, managed by progressively decreasing sedation as required, and once overcome, we followed the previously mentioned protocol, including a brief spontaneous breathing trial, progressive downsizing of the tracheostomy tube and increasingly longer periods of cuff deflation. A hemicannula was always employed to maintain access in case recannulation was required. After decannulation, 2 patients required recannulation, which was easily done thanks to the hemicannula. The average time until the hemi-cannula was removed was $4+/-2$ days. Time till total decannulation was shorter than previously published by other groups ${ }^{51}$. 
Regarding the limitations of this study, we should point out that the results of the neural network are not superior to those of the logistic regression, since this tool needs a larger cohort in order to learn and thus improve its predictive capacity. Despite this, the results it offers are confirmed by the logistical analysis. Additionally, it is a very useful tool in case it is used in multicenter cohorts. Also the study has no control braches, and use retrospectively observational data. This is a descriptive study, performed under a common clinical protocol of the entire hospital, in which it tries to identify variables that may have a greater relationship with a worse patient prognosis. Given the descriptive, retrospective, single-center nature of the study, no definitive conclusions can be drawn. These are indicative results that should be established under randomized clinical trials.

\section{Conclusions}

The IRCU prevented the collapse of the ICU without increasing mortality. IRCU risk factors associated with mortality were cardiorespiratory, hemodynamic alterations and fever, indicating a poorer prognosis. The therapeutic options, which offered the best results, were related to corticoids, anticoagulants and some antirheumatics. In our series, HFO and weaning are the procedures most related to survival, while CPAP and NIMV with a protective profile were able to contain mortality in the most severe cases. Mortality did not increase with the evident delay in intubation in those cases where it was not avoidable. 
Tables

Supplementary Table 1. Inpatient clinical practice guidelines in COVID19 pneumonia Jimenez Diaz Foundation University Hospital Quironsalud group.

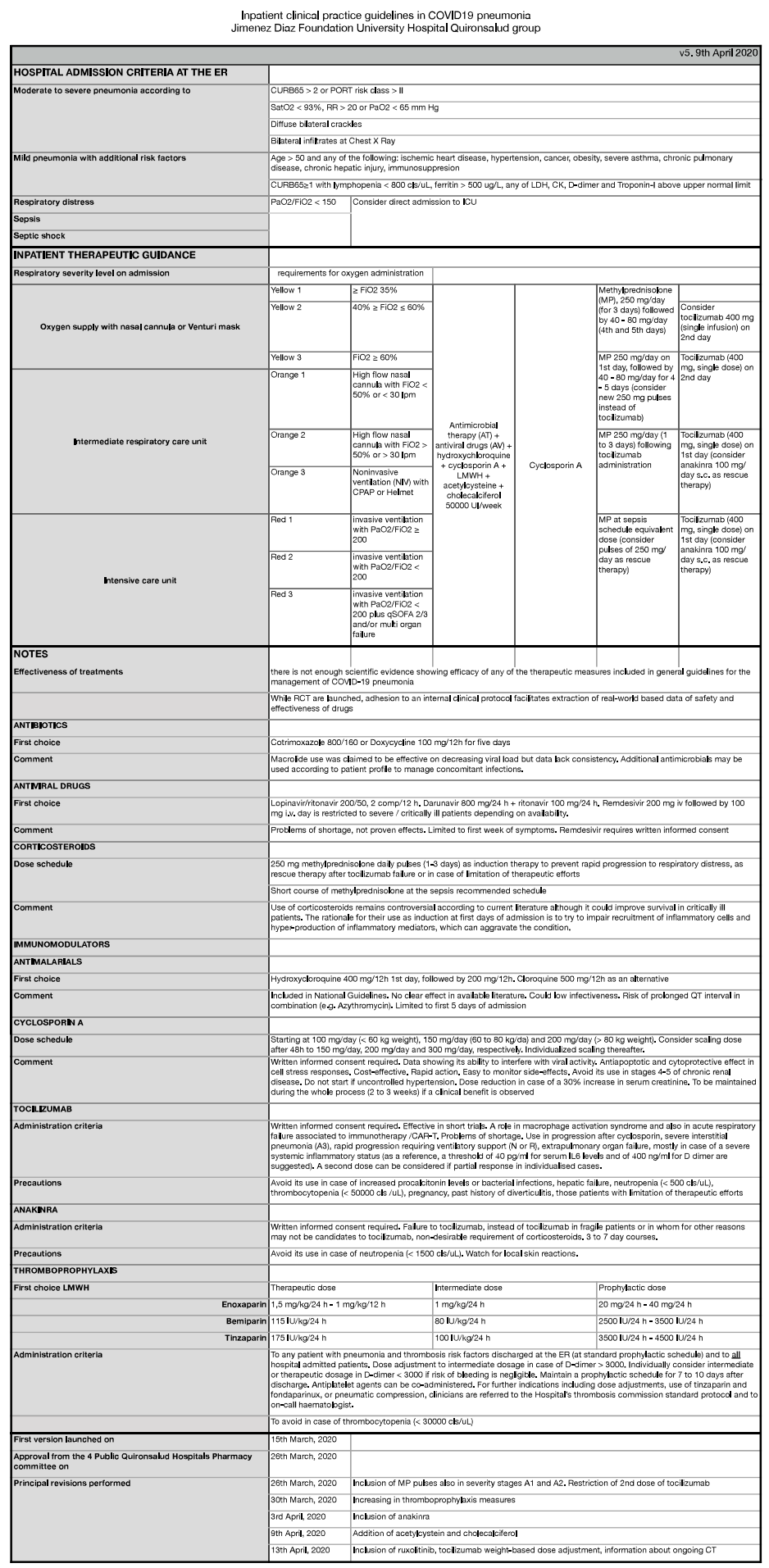


Table 1

Comorbidities

Exitus vs. rest 274 patients. Univariate, Multivariate Logistic regression analysis and Hosmer and Lemeshow test.

\begin{tabular}{|c|c|c|c|c|c|c|}
\hline \multirow[b]{2}{*}{ Risk factor } & \multicolumn{3}{|c|}{ UNIVARIABLE } & \multicolumn{3}{|c|}{ MULTIVARIABLE $^{1}$} \\
\hline & OR & $(95 \% \mathrm{Cl})$ & $\mathbf{P}$ & OR & $(95 \% \mathrm{Cl})$ & $\mathbf{P}$ \\
\hline Smoker & 1.1 & $(0.56,2.11)$ & 0.784 & & & \\
\hline Cardiac_Disease & 1.8 & $(0.86,3.61)$ & 0.116 & & & \\
\hline Pulmonary_Disease & 1.82 & $(0.90,3.58)$ & 0.094 & 1.82 & $(0.90,3.58)$ & 0.094 \\
\hline Diabetes & 1.12 & $(0.47,2.42)$ & 0.787 & & & \\
\hline Renal_Disease & 0.59 & $(0.09,2.18)$ & 0.466 & & & \\
\hline Neurological_Disorder & 1.68 & $(0.67,3.87)$ & 0.259 & & & \\
\hline Oncological_Disease & 1.33 & $(0.36,3.88)$ & 0.639 & & & \\
\hline Hypertension & 1.4 & $(0.73,2.67)$ & 0.309 & & & \\
\hline
\end{tabular}

${ }^{1}$ Hosmer and Lemeshow test: $\mathrm{p}=1$

Table 2

\section{Comorbidities}

Exitus vs. ICU 130 patients . Univariate, Multivariate Logistic regression analysis and Hosmer and Lemeshow test.

\begin{tabular}{lcccccc}
\hline Risk factor & OR & $\begin{array}{c}\text { UNIVARIABLE } \\
(\mathbf{9 5 \%} \text { Cl) }\end{array}$ & P & OR & $\begin{array}{c}\text { MULTIVARIABLE }^{1} \\
(95 \% \text { CI) }\end{array}$ & P \\
\hline Smoker & 1.67 & $(0.72,3.79)$ & 0.229 & & & \\
Cardiac_Disease & 3.22 & $(1.21,8.56)$ & 0.020 & & & 0.03 \\
Pulmonary_Disease & 2.73 & $(1.11,6.62)$ & 0.028 & 2.93 & $(1.08,7.86)$ & 4 \\
Diabetes & 1.52 & $(0.53,4.06)$ & 0.423 & & & 0.11 \\
Renal_Disease & 0.94 & $(0.05,7.63)$ & 0.957 & 0.10 & $(0.00,1.61)$ & 1 \\
Neurological_Disorder & 2.51 & $(0.83,7.37)$ & 0.102 & & & 0.00 \\
Oncological_Disease & 6.27 & $(1.16,46.8)$ & 0.033 & 15.3 & $(1.94,321)$ & 9 \\
& & & & & & 0.01 \\
Hypertension & 3.24 & $(1.45,7.39)$ & 0.004 & 2.99 & $(1.27,7.19)$ & 3 \\
\hline 1 Hosmer and Lemeshow test: $\mathrm{p}=1$ & & & & &
\end{tabular}

\footnotetext{
${ }^{1}$ Hosmer and Lemeshow test: $\mathrm{p}=1$
} 
Table 3

Vital signs

Exitus vs. rest 274 patients. Univariate, Multivariate Logistic regression analysis and Hosmer and Lemeshow test.

\begin{tabular}{|c|c|c|c|c|c|c|}
\hline \multirow[b]{2}{*}{ Vital sign } & \multicolumn{3}{|c|}{ UNIVARIABLE } & \multicolumn{3}{|c|}{ MULTIVARIABLE $^{1}$} \\
\hline & OR & $(95 \% \mathrm{Cl})$ & $\mathbf{P}$ & OR & $(95 \% \mathrm{Cl})$ & $\mathbf{P}$ \\
\hline First_Saturation & 0.98 & $(0.94,1.02)$ & 0.309 & & & \\
\hline Min_Saturation & 0.95 & $(0.93,0.97)$ & $<0.001$ & 0.95 & $(0.92,0.97)$ & $<0.001$ \\
\hline Max_Saturation & 0.73 & $(0.61,0.86)$ & $<0.001$ & 0.74 & $(0.58,0.90)$ & 0.001 \\
\hline First_SBP & 1.00 & $(0.98,1.01)$ & 0.932 & 1.02 & $(1.00,1.04)$ & 0.050 \\
\hline Min_SBP & 1.02 & $(0.98,1.06)$ & 0.257 & 0.98 & $(0.96,1.00)$ & 0.088 \\
\hline Max_SBP & 1.01 & $(1.00,1.01)$ & 0.272 & 0.95 & $(0.89,1.00)$ & 0.063 \\
\hline First_DBP & 0.98 & $(0.95,1.00)$ & 0.098 & & & \\
\hline Min_DBP & 0.99 & $(0.97,1.00)$ & 0.042 & & & \\
\hline Max_DBP & 0.95 & $(0.91,0.98)$ & 0.006 & & & \\
\hline First_Heart_Rate & 1.00 & $(0.98,1.01)$ & 0.705 & & & \\
\hline Min_Heart_Rate & 1.03 & $(1.00,1.06)$ & 0.039 & & & \\
\hline Max_Heart_Rate & 1.01 & $(0.99,1.03)$ & 0.261 & 1.03 & $(1.01,1.05)$ & 0.011 \\
\hline First_Temperature & 1.00 & $(0.70,1.41)$ & 0.993 & & & \\
\hline Min_Temperature & 2.89 & $(1.42,6.26)$ & 0.003 & 2.16 & $(0.91,5.41)$ & 0.082 \\
\hline Max_Temperature & 1.21 & $(0.83,1.78)$ & 0.321 & 1.51 & $(0.92,2.50)$ & 0.105 \\
\hline
\end{tabular}

${ }^{1}$ Hosmer and Lemeshow test: $p=0.773$

\section{Table 4}

\section{Vital signs}

Exitus vs. ICU 130 patients . Univariate, Multivariate Logistic regression analysis and Hosmer and Lemeshow test.

\begin{tabular}{lcccccc}
\hline Vital sign & OR & $\begin{array}{c}\text { UNIVARIABLE } \\
(95 \% \text { Cl) }\end{array}$ & P & OR & $(95 \%$ Cl) & P \\
\hline First_Saturation & 0.99 & $(0.93,1.05)$ & 0.619 & & & \\
Min_Saturation & 0.93 & $(0.90,0.96)$ & $<0.001$ & 0.95 & $(0.92,0.98)$ & 0.003 \\
Max_Saturation & 0.45 & $(0.30,0.62)$ & $<0.001$ & 0.36 & $(0.21,0.57)$ & $<0.001$ \\
First_SBP & 1.00 & $(0.98,1.02)$ & 0.928 & 1.04 & $(1.01,1.07)$ & 0.014 \\
Min_SBP & 1.05 & $(1.00,1.11)$ & 0.063 & 1.07 & $(0.98,1.17)$ & 0.139 \\
Max_SBP & 1.00 & $(0.99,1.01)$ & 0.530 & & & \\
First_DBP & 0.97 & $(0.94,1.00)$ & 0.022 & 0.94 & $(0.90,0.98)$ & 0.008 \\
Min_DBP & 0.99 & $(0.97,1.01)$ & 0.269 & & & \\
Max_DBP & 0.94 & $(0.90,0.99)$ & 0.014 & & & \\
First_Heart_Rate & 0.99 & $(0.96,1.01)$ & 0.362 & & & \\
Min_Heart_Rate & 1.02 & $(0.99,1.06)$ & 0.176 & & & \\
Max_Heart_Rate & 1.00 & $(0.98,1.02)$ & 0.941 & 1.04 & $(1.01,1.07)$ & 0.015 \\
First_Temperature & 0.73 & $(0.47,1.10)$ & 0.136 & & & \\
Min_Temperature & 2.44 & $(1.06,6.11)$ & 0.037 & & & \\
Max_Temperature & 0.63 & $(0.38,1.01)$ & 0.056 & & & \\
\hline 1 Hast & & & & \\
\end{tabular}

${ }^{1}$ Hosmer and Lemeshow test: $p=0.114$ 


\section{Table 5}

\section{Drugs}

Exitus vs. rest 274 patients. Univariate, Multivariate Logistic regression analysis and Hosmer and Lemeshow test.

\begin{tabular}{lcccccc}
\hline & \multicolumn{3}{c}{ UNIVARIABLE } & \multicolumn{3}{c}{ MULTIVARIABLE $^{1}$} \\
Drug & OR & $\mathbf{( 9 5 \% ~ C l )}$ & $\mathbf{P}$ & OR & $\mathbf{( 9 5 \% ~ C l )}$ & P \\
\hline Amoxicillin & 1.38 & $(0.48,3.42)$ & 0.524 & 2.35 & $(0.78,6.36)$ & 0.123 \\
Azithromycin & 2.19 & $(0.75,5.77)$ & 0.145 & & & \\
Beta_Interferon & 1.05 & $(0.49,2.11)$ & 0.900 & & & \\
Ceftriaxone & 0.69 & $(0.33,1.36)$ & 0.286 & & & \\
Cloroquine_Hydroxychloroquine & 0.94 & $(0.49,1.79)$ & 0.858 & & & \\
Erythromycin & 0.67 & $(0.19,1.83)$ & 0.462 & & & \\
Levofloxacin & 0.74 & $(0.37,1.42)$ & 0.364 & & & \\
Lopinavir & 1.03 & $(0.53,2.05)$ & 0.930 & & & \\
Meropenem & 1.33 & $(0.54,3.00)$ & 0.518 & & & \\
Cyclosporine & 1.06 & $(0.56,2.02)$ & 0.867 & & & \\
Tocilizumab & 0.93 & $(0.46,1.81)$ & 0.836 & & & \\
Doxycycline & 0.9 & $(0.47,1.76)$ & 0.758 & & & \\
Dexamethasone & 0.43 & $(0.16,1.01)$ & 0.052 & 0.30 & $(0.09,0.76)$ & 0.010 \\
Methylprednisolone & 1.31 & $(0.68,2.59)$ & 0.424 & & & \\
Bemiparine & 0.94 & $(0.49,1.79)$ & 0.858 & & & \\
Enoxaparin & 0.87 & $(0.45,1.69)$ & 0.675 & & & \\
Tinzaparin & 3.63 & $(0.89,13.3)$ & 0.069 & 6.78 & $(1.48,31.0)$ & 0.015 \\
Anakinra & 1.97 & $(0.42,7.14)$ & 0.354 & & & \\
Acetylcysteine & 0.68 & $(0.36,1.32)$ & 0.250 & & & \\
\hline
\end{tabular}

${ }^{1}$ Hosmer and Lemeshow test: $p=1$ 


\section{Table 6}

\section{Drugs}

Exitus vs. ICU 130 patients. Univariate, Multivariate Logistic regression analysis and Hosmer and Lemeshow test.

\begin{tabular}{lcccccc}
\hline & \multicolumn{3}{c}{ UNIVARIABLE } & \multicolumn{3}{c}{ MULTIVARIABLE $^{1}$} \\
Drug & OR & $(95 \%$ Cl) & P & OR & (95\% Cl) & P \\
\hline Amoxicillin & 3.21 & $(0.94,11.1)$ & 0.063 & 13.6 & $(1.35,174)$ & 0.027 \\
Azithromycin & 0.83 & $(0.18,2.93)$ & 0.788 & & & \\
Beta_Interferon & 0.29 & $(0.10,0.72)$ & 0.007 & 0.06 & $(0.01,0.43)$ & 0.004 \\
Ceftriaxone & 0.45 & $(0.19,1.03)$ & 0.058 & & & \\
Cloroquine_Hydroxychloroquine & 0.56 & $(0.25,1.24)$ & 0.153 & 0.28 & $(0.05,1.19)$ & 0.086 \\
Levofloxacin & 0.8 & $(0.35,1.78)$ & 0.583 & & & \\
Lopinavir & 0.25 & $(0.11,0.60)$ & 0.002 & 7.96 & $(1.26,67.2)$ & 0.026 \\
Meropenem & 0.27 & $(0.07,0.75)$ & 0.010 & & & \\
Cyclosporine & 0.28 & $(0.12,0.64)$ & 0.003 & & & \\
Tocilizumab & 0.22 & $(0.09,0.50)$ & $<0.001$ & 0.35 & $(0.08,1.44)$ & 0.143 \\
Doxycycline & 0.23 & $(0.10,0.56)$ & 0.001 & & & \\
Dexamethasone & 0.08 & $(0.02,0.25)$ & $<0.001$ & 0.00 & $(0.00,0.03)$ & $<0.001$ \\
Methylprednisolone & 1.2 & $(0.53,2.83)$ & 0.666 & 12.1 & $(2.11,114)$ & 0.004 \\
Bemiparine & 0.59 & $(0.26,1.29)$ & 0.186 & & & \\
Enoxaparin & 0.04 & $(0.01,0.12)$ & $<0.001$ & 0.01 & $(0.00,0.10)$ & $<0.001$ \\
Tinzaparin & 3.07 & $(0.69,13.7)$ & 0.136 & 34.5 & $(2.27,1237)$ & 0.010 \\
Anakinra & 0.45 & $(0.02,2.80)$ & 0.436 & & & \\
Acetylcysteine & 0.13 & $(0.05,0.32)$ & $<0.001$ & & & \\
\hline 1Hosmand & & & & &
\end{tabular}

${ }^{1}$ Hosmer and Lemeshow test: $\mathrm{p}=0.998$ 


\section{FIGURE LEGENDS}

Supplementary Figure 1. Demographics Analysis of 274 patients. A) Gender and Anthropometrics. B) Age Distribution C) Comorbidities. D) Drugs frequency used

Figure 1. Outcomes. Analysis of 274 patients. A) Outcomes B) Mortality related to age C) Daily number of Dead in IRCU D) Time sections mortality from March to May 2020. E) Admissions, ICU transfer and Mortality over time.

Supplementary Figure 2. Patients cohort using Helmet. A) Comorbidities and drug consumption B) Biomarkers C) Vital signs of the global cohort (274 patients) D) Vital signs of the Helmet cohort (6 patients)

Figure 2. Comorbidities in dead and non-dead admitted patients. Analysis of 274 patients. A) all ages. PCA analysis, NN ROCs, importance in NN model, and Fisher test results, sorted by relative odd ratios. Significance taken as FDR<0.05. B) 50-70 years-old. PCA analysis, NN ROCs, importance in NN model, and Fisher test results, sorted by relative odd ratios. Significance taken as FDR $<0.05$. C) $>70$ years-old. PCA analysis, NN ROCs, importance in NN model, and Fisher test results, sorted by relative odd ratios. Significance taken as FDR<0.05.

Supplementary Figure 3. Comorbidities in dead and ICU transfered patients. Analysis of 130 patients. A) all ages. PCA analysis, B) NN ROCs, C) importance in NN model, and D) Fisher test results, sorted by relative odd ratios. Significance taken as FDR $<0.05$.

Supplementary Figure 4. Logistic regression analysis Roc curve for comorbidities. A) overall population. B) More severe patients (dead and ICU transferred patients)

Figure 3. Vital Signs in dead and non-dead admitted patients. Analysis of 274 patients. A) all ages. PCA analysis, NN ROCs, importance in NN model, and Fisher test results, sorted by relative odd ratios. Significance taken as FDR<0.05. B) 50-70 years-old. PCA analysis, NN ROCs, importance in NN model, and Fisher test results, sorted by relative odd ratios. Significance taken as FDR $<0.05$. C) $>70$ years-old. PCA analysis, NN ROCs, importance in NN model, and Fisher test results, sorted by relative odd ratios. Significance taken as FDR<0.05.

Supplementary Figure 5. Vital Signs in dead and ICU transferred patients. Analysis of 130 patients. A) all ages. PCA analysis, B) NN ROCs, C) importance in NN model, and D) Fisher test results, sorted by relative odd ratios. Significance taken as FDR $<0.05$.

Supplementary Figure 6. Logistic regression analysis Roc curve for Vital Signs. A) overall population. B) More severe patients (dead and ICU transferred patients)

Figure 4. Drugs consumption in dead and non-dead admitted patients. A) 50-70 years-old. PCA analysis, NN ROCs, importance in NN model, and Fisher test results, sorted by relative odd ratios. Significance taken as FDR $<0.05$. B) $>70$ years-old. PCA analysis, NN ROCs, importance in NN model, and Fisher test results, sorted by relative odd ratios. Significance taken as FDR<0.05. C) all ages ICU transferred vs. dead. PCA analysis, NN ROCs, importance in NN model, and Fisher test results, sorted by relative odd ratios. Significance taken as FDR<0.05.

Supplementary Figure 7. Drug consumption in dead and ICU transferred patients $>\mathbf{7 0}$ years. Analysis of 37 patients. A) PCA analysis, B) NN ROCs, C) importance in NN model, and D) Fisher test results, sorted by relative odd ratios. Significance taken as FDR $<0.05$.

Supplementary Figure 8. Logistic regression analysis Roc curve for Vital Signs. A) overall population. B) More severe patients (dead and ICU transferred patients) 
Figure 5. Respiratory Support demographics. A) Respiratory support in alive and dead. Fisher test. B) Parameters (mean and sd) used with every technique. C) Comparison between parameters related to respiratory support (t-student test)

Figure 6. Respiratory support in dead and non-dead admitted patients. A) all ages. PCA analysis, B) NN ROCs, C) importance in NN model, and Fisher test results, sorted by relative odd ratios. Significance taken as FDR<0.05. B) $>70$ years-old. PCA analysis, B) NN ROCs, C) importance in NN model, and Fisher test results, sorted by relative odd ratios. Significance taken as FDR<0.05. 
Figures

Supplementary Figure 1.

A

Gender
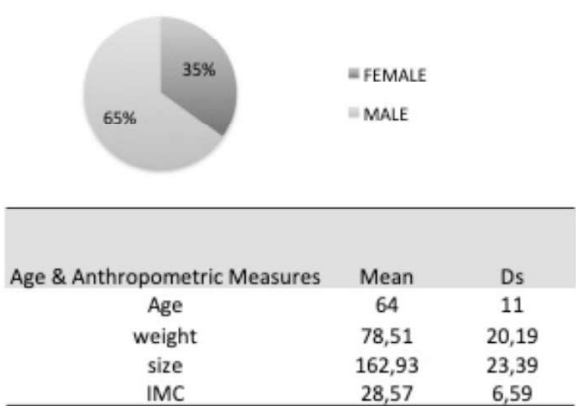

B

Age Distribution

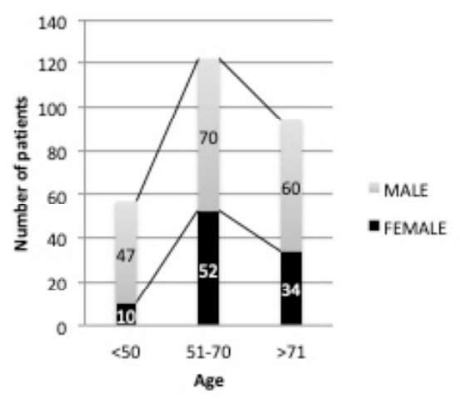

C

Risk Factors Distribution

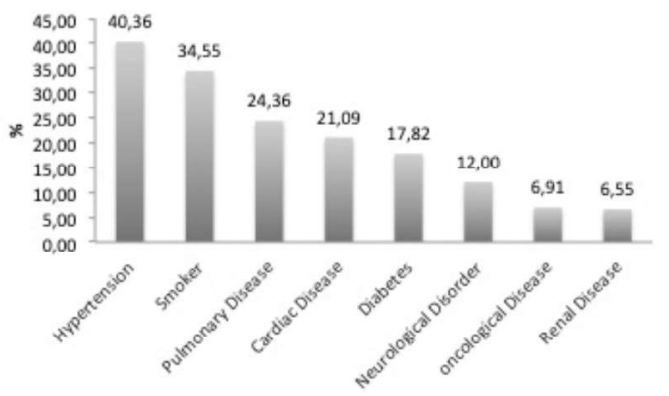

D Drugs \% Use

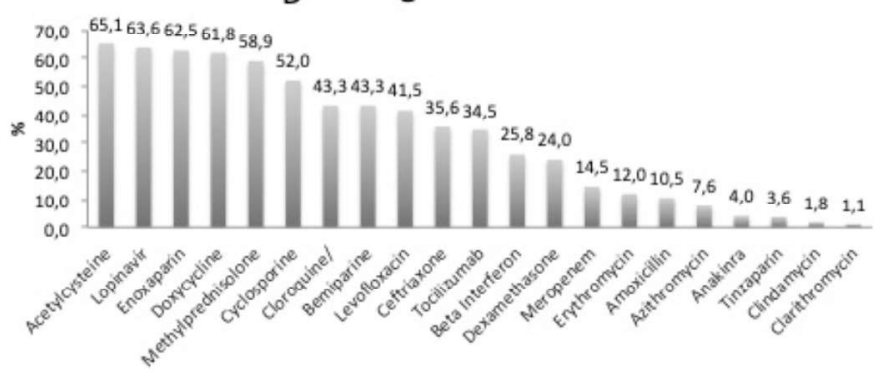




\section{Figure 1}

\begin{tabular}{|c|c|c|c|}
\hline IRCU PATIENTS & N 274 & $\%$ \\
\hline \multirow{2}{*}{ Ircu Admission With Outcome Alive } & 144 & 52,5 \\
\hline Ircu Admission With Outcome Dead (Ircu failure) & 34 & 12,4 \\
\hline Ircu Success (Survivals And Achieved Icu Transfer) & 240 & 87,59 \\
\hline Transfer To Icu Alive & 96 & 35 \\
\hline Delaved Dead In Icu (Delaved Ircu Failure) & 11 & $6 \%$ \\
\hline \multicolumn{2}{|c|}{} \\
\hline
\end{tabular}

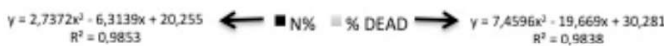

Delaved Dead In Icu (Delaved Ircu Failure

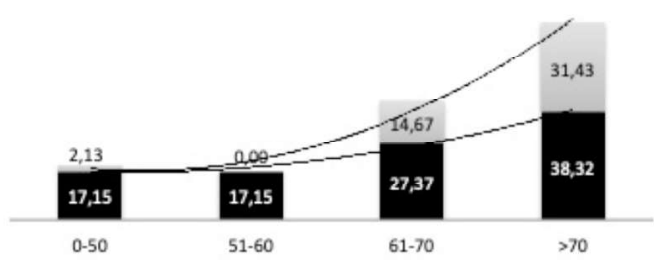

C

\section{Daily Number of Dead}

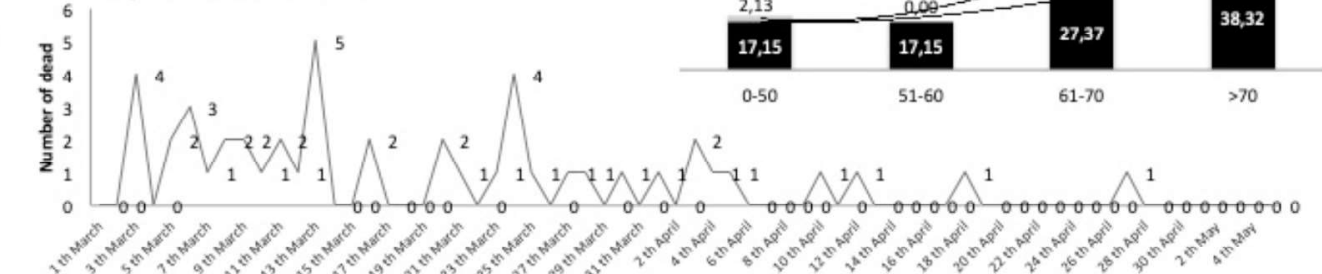

D Time Sections Mortality

\section{E IRCU Time Evolution on March and}
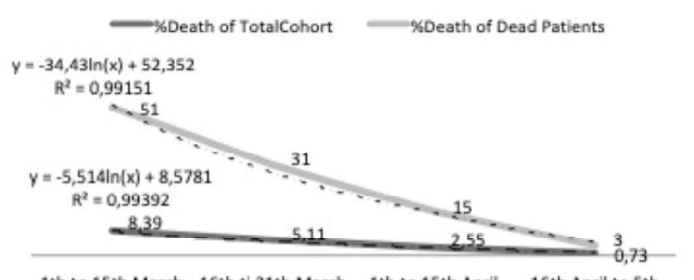

1th to 15 th March 16th ti 31th March 1th to 15th April 16th April to 5th April 2020

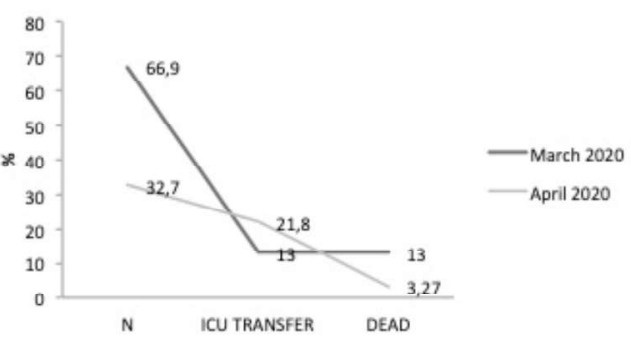




\section{Supplementary Figure 2}

A

\begin{tabular}{cccccc}
\hline Helmet Comorbidity \% & Hypertension & Respiratory Disease & Oncological Disease & Diabetes & Tobacco \\
\hline & 83,00 & 50 & 50 & 16,6 & 16,6 \\
\hline Helmet Cohort Drug \% & Lopinavir & Beta Interferon & Cyclosporine & Tocilizumab & Esteroids \\
\hline & 100 & 50 & 75 & 16,6 & 33 \\
\hline
\end{tabular}

B

\begin{tabular}{|c|c|c|c|c|c|c|c|c|c|c|c|c|}
\hline HELMET & LEUCOCYTES & HEMOGLOAIN & PLATLLETS & VSG & CALATINENE & soolum & POTASIUM & FEARITINE & 116 & CPK & D DIMER & LDH \\
\hline MEAN & 15702,67 & 13,00 & 236187,17 & 119,67 & 0,58 & 131,33 & 4,30 & 1484,00 & 10,67 & 229,00 & 3512,67 & 864,33 \\
\hline DS & 2281,60 & 1,26 & 40336,69 & 24,60 & 0,16 & 2,58 & 0,57 & 247,04 & 3,50 & 130,73 & 1675,03 & 196,38 \\
\hline
\end{tabular}

C

\begin{tabular}{ccc}
\hline Vital Signs n=274 & Mean & Ds \\
First_Saturation & 90,01 & 6,93 \\
Min_Saturation & 87,69 & 13,74 \\
Max_Saturation & 98,01 & 1,97 \\
First_SBP & 128,26 & 22,52 \\
Min_SBP & 103,76 & 13,66 \\
Max_SBP & 122,98 & 34,70 \\
First_DBP & 73,36 & 13,12 \\
Min_DBP & 64,91 & 26,30 \\
Max_DBP & 89,31 & 7,59 \\
First_Heart_Rate & 89,28 & 18,39 \\
Min_Heart_Rate & 58,87 & 13,05 \\
Max_Heart_Rate & 108,00 & 17,53 \\
First_Temperature & 37,03 & 2,42 \\
Min_Temperature & 34,64 & 5,22 \\
Max_Temperature & 37,86 & 2,44 \\
\hline
\end{tabular}

D

\begin{tabular}{ccc}
\hline Helmet vital Signs $\mathrm{n}=6$ & Mean & Ds \\
First_Saturation & 86,3 & 5,8 \\
Min_Saturation & 79,5 & 5,1 \\
Max_Saturation & 97,3 & 1,5 \\
First_SBP & 138,3 & 11,3 \\
Min_SBP & 105,5 & 3,5 \\
Max_SBP & 167,8 & 12,7 \\
First_DBP & 60,8 & 5,3 \\
Min_DBP & 39,5 & 10,1 \\
Max_DBP & 75,5 & 7,9 \\
First_Heart_Rate & 75,8 & 6,9 \\
Min_Heart_Rate & 55,8 & 8,4 \\
Max_Heart_Rate & 120,8 & 23,5 \\
First_Temperature & 37,5 & 0,9 \\
Min_Temperature & 35,8 & 0,5 \\
Max_Temperature & 38,7 & 0,3 \\
\hline
\end{tabular}




\section{Figure 2}

A Dead vs Rest All ages $n=266$
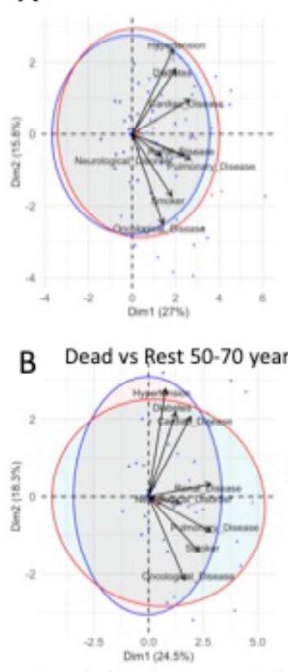

C Dead vs Rest $>70$ years $n=94$

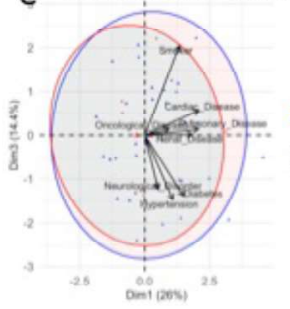

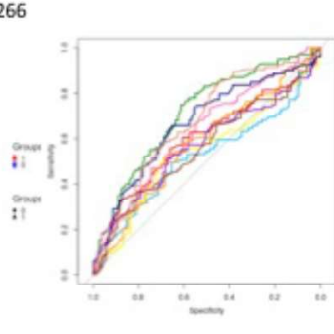
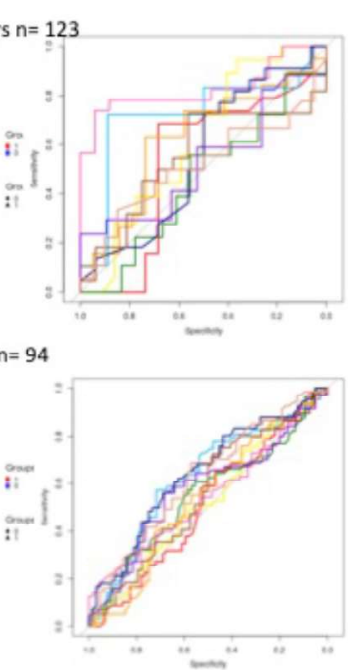

odds ratio

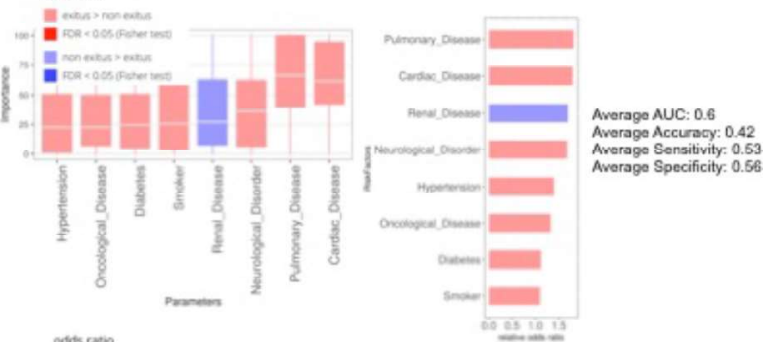

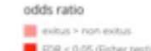
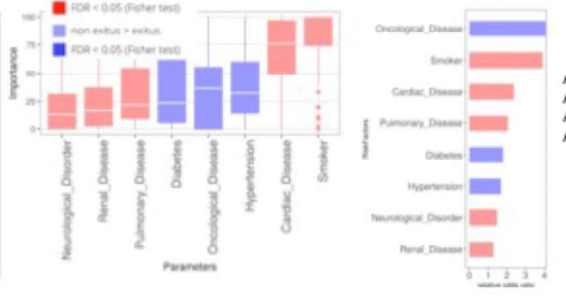

Average AuC: 0.81 Average Aocuracy: 0.56 Average Sensitivity: 0.61

odds ratio

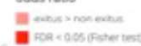

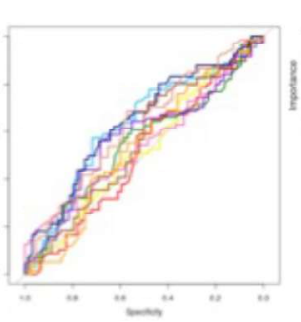

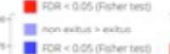

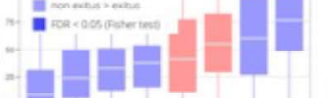

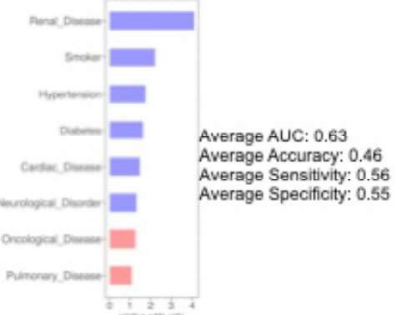

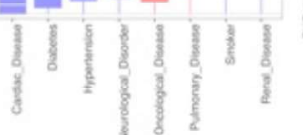




\section{Supplementary Figure 3}
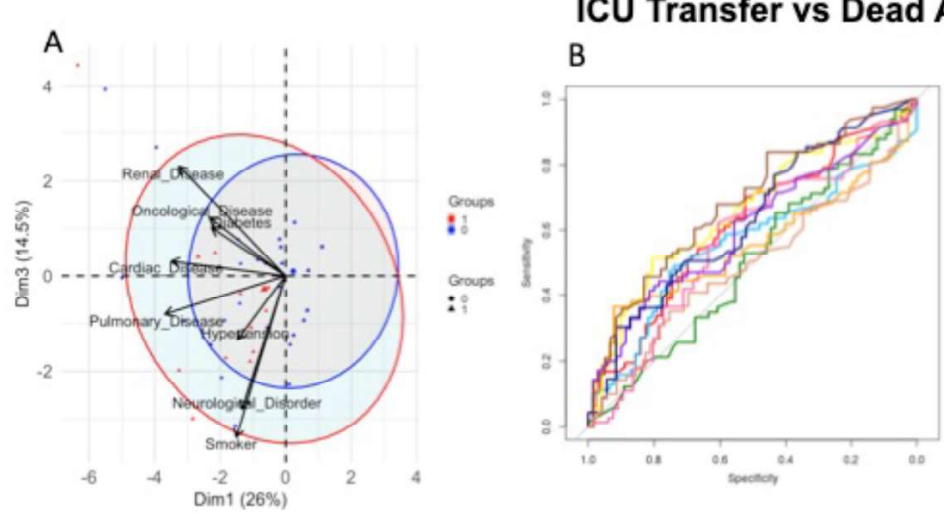

ICU Transfer vs Dead ALL AGES (130 patients)

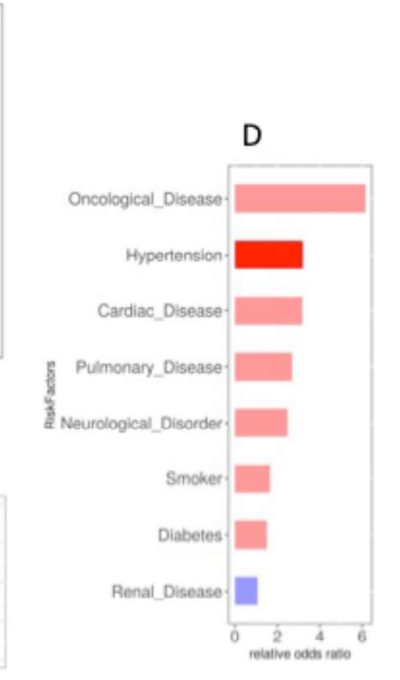

Red $\rightarrow$ ratio higher in exitus

Blue $\rightarrow$ ratio higher in ICU

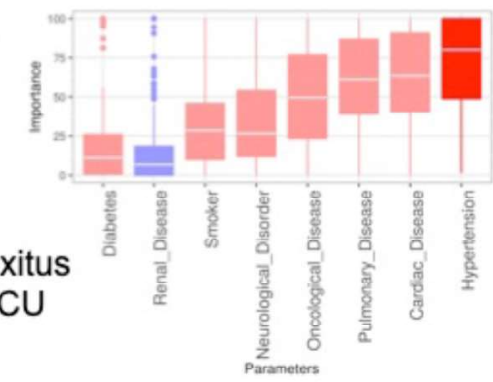




\section{Supplementary Figure 4}

A

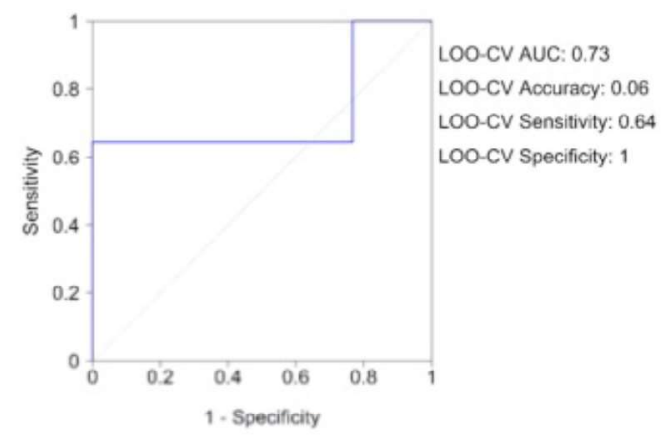

B

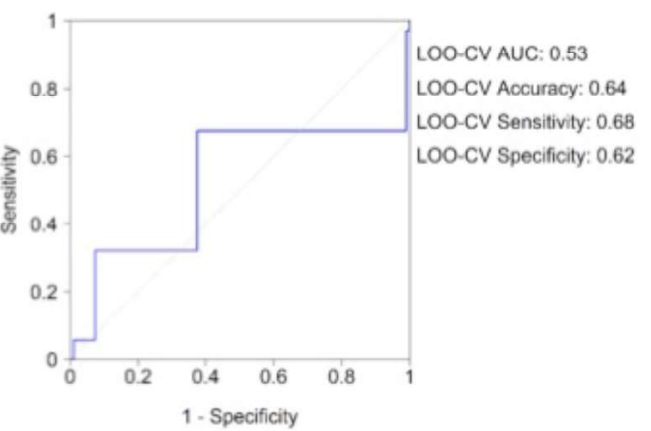


Figure 3
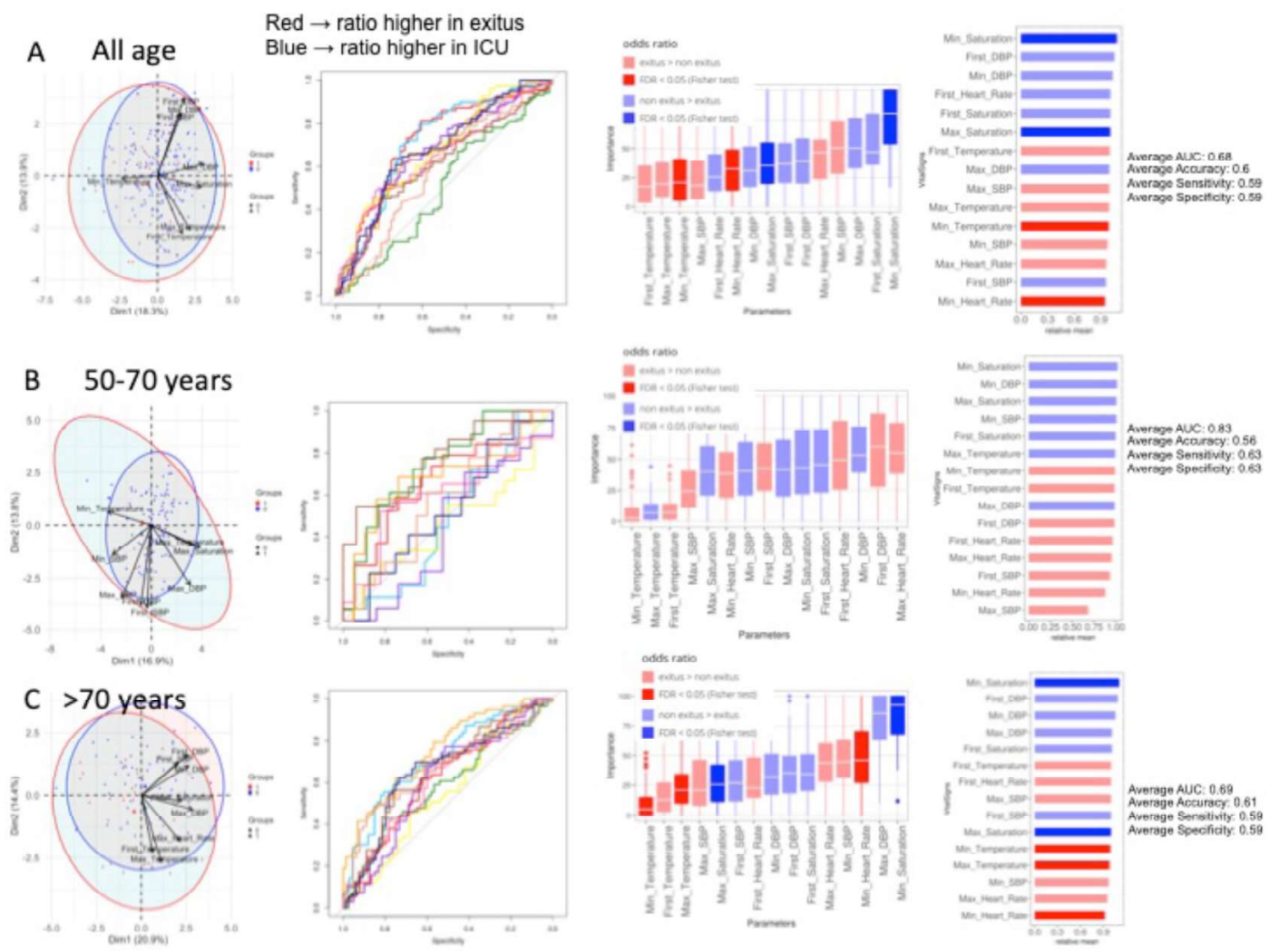


\section{Supplementary Figure 5}

\section{ICU Transfer vs dead ALL AGES (130 patients)}
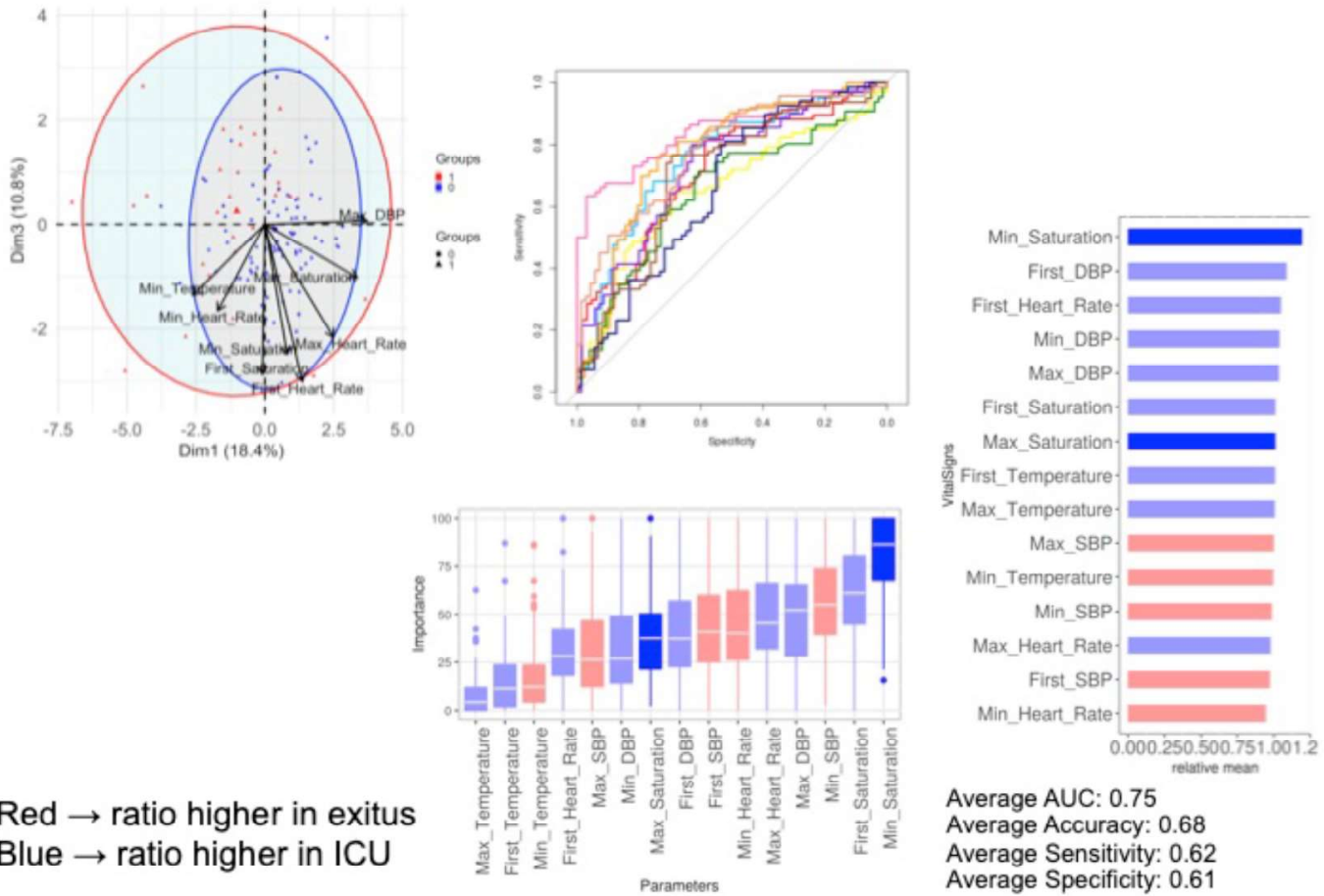

Red $\rightarrow$ ratio higher in exitus Blue $\rightarrow$ ratio higher in ICU Parameters

Average AUC: 0.75

Average Accuracy: 0.68

Average Sensitivity: 0.62 Average Specificity: 0.61 


\section{Supplementary Figure 6}

A

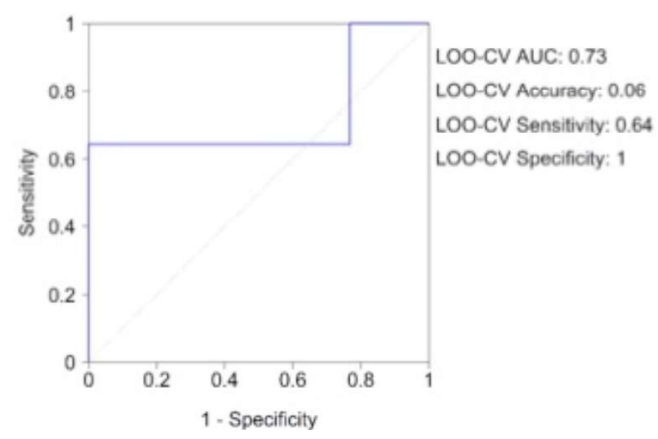

B

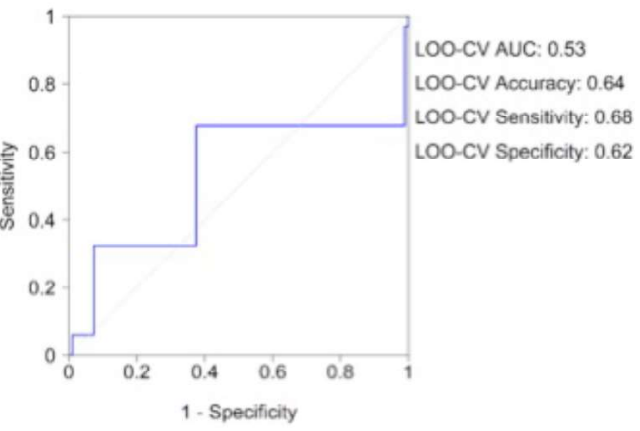




\section{Figure 4}

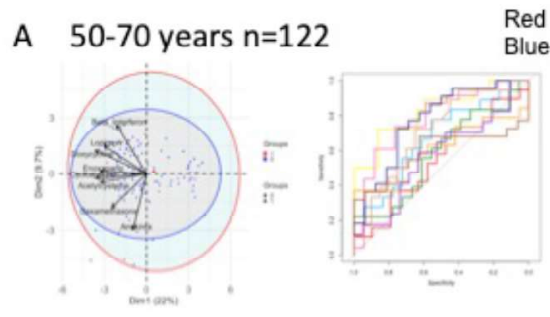

B $>70$ years $n=94$
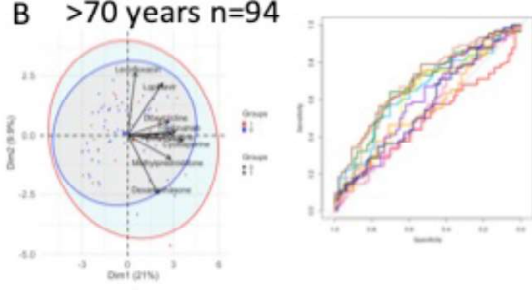

ed $\rightarrow$ ratio higher in exitus

$\mathrm{ue} \rightarrow$ ratio higher in ICU
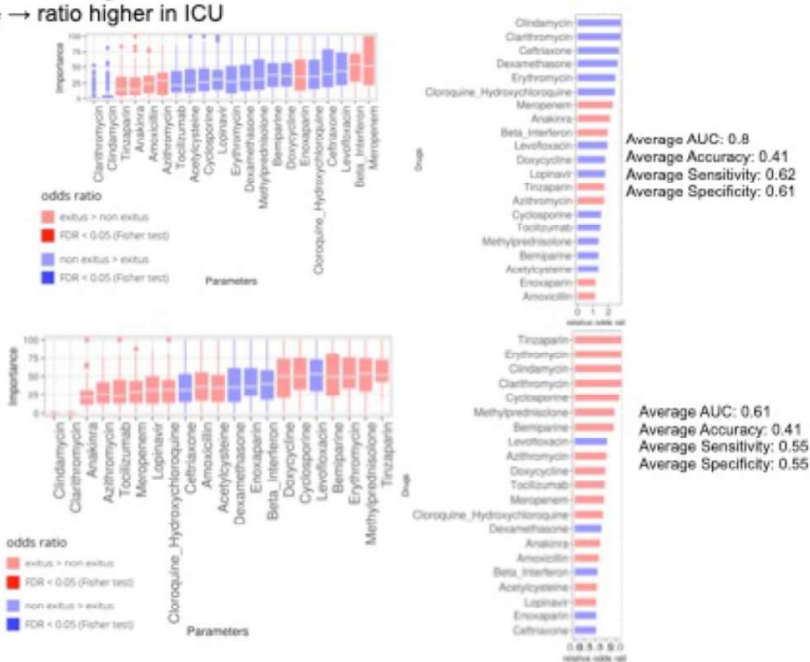

C All Ages (Most Severe.ICU transfer and Dead $n=130$ )
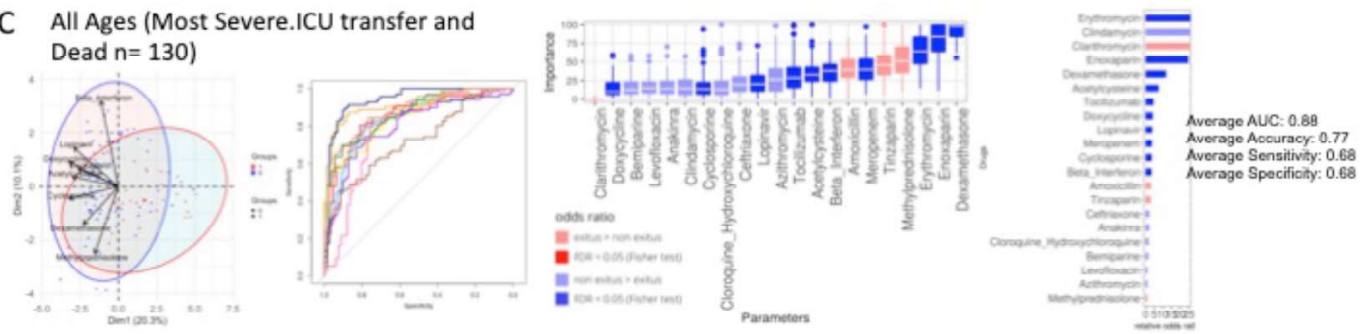


\section{Supplementary Figure 7}

ICU Transfer vs Dead 70-100 AGES (37 patients)
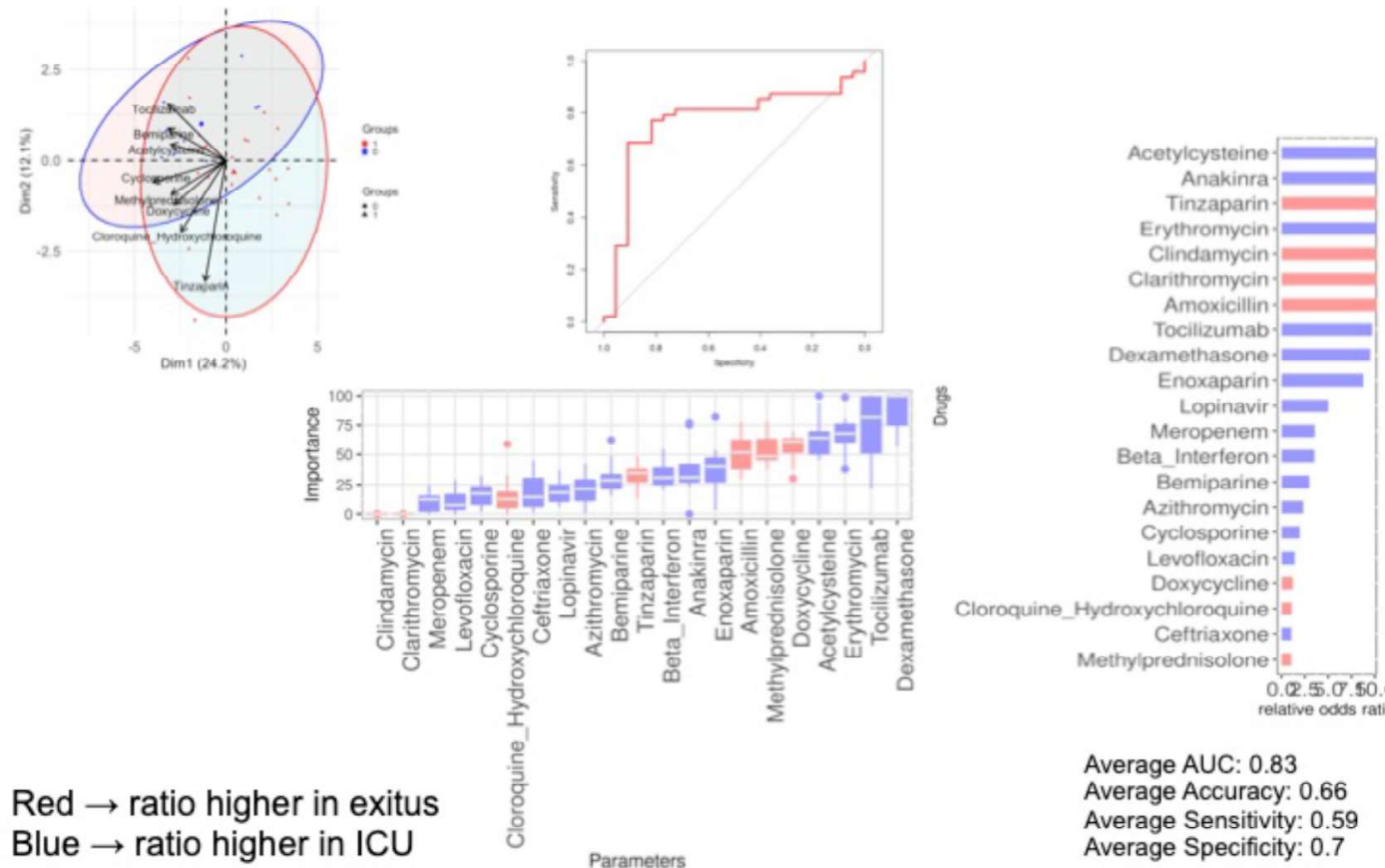

Red $\rightarrow$ ratio higher in exitu
Blue $\rightarrow$ ratio higher in ICU

Parameters 


\section{Supplementary Figure 8}

A

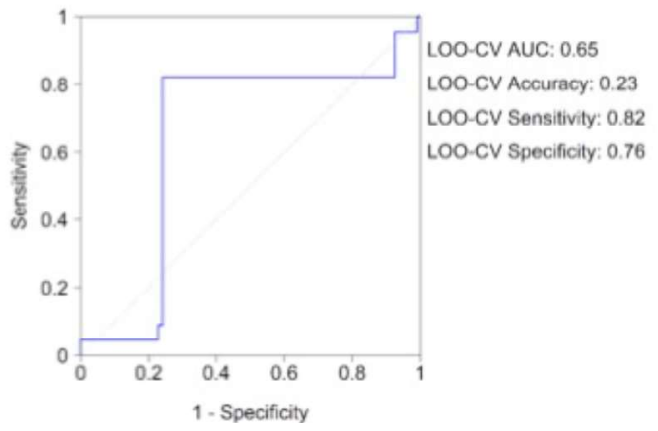

B

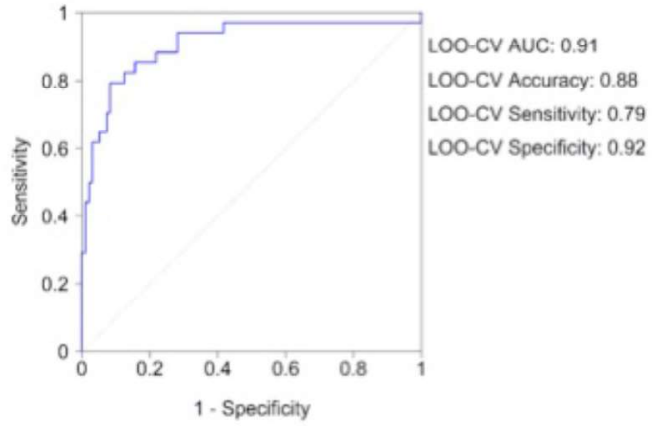


Figure 5

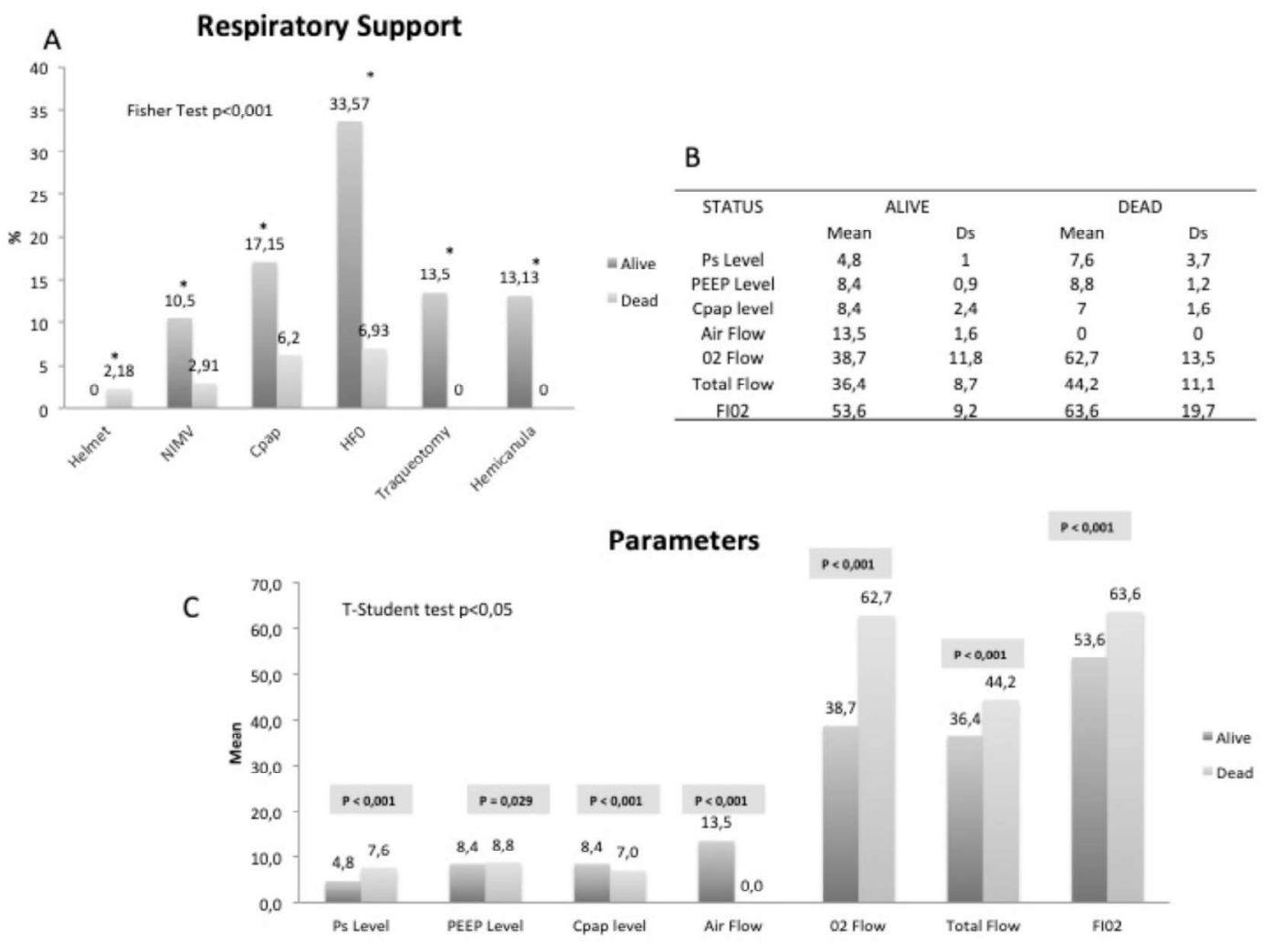


Figure 6

A Respiratory support Dead vs Rest all ages $n=142$
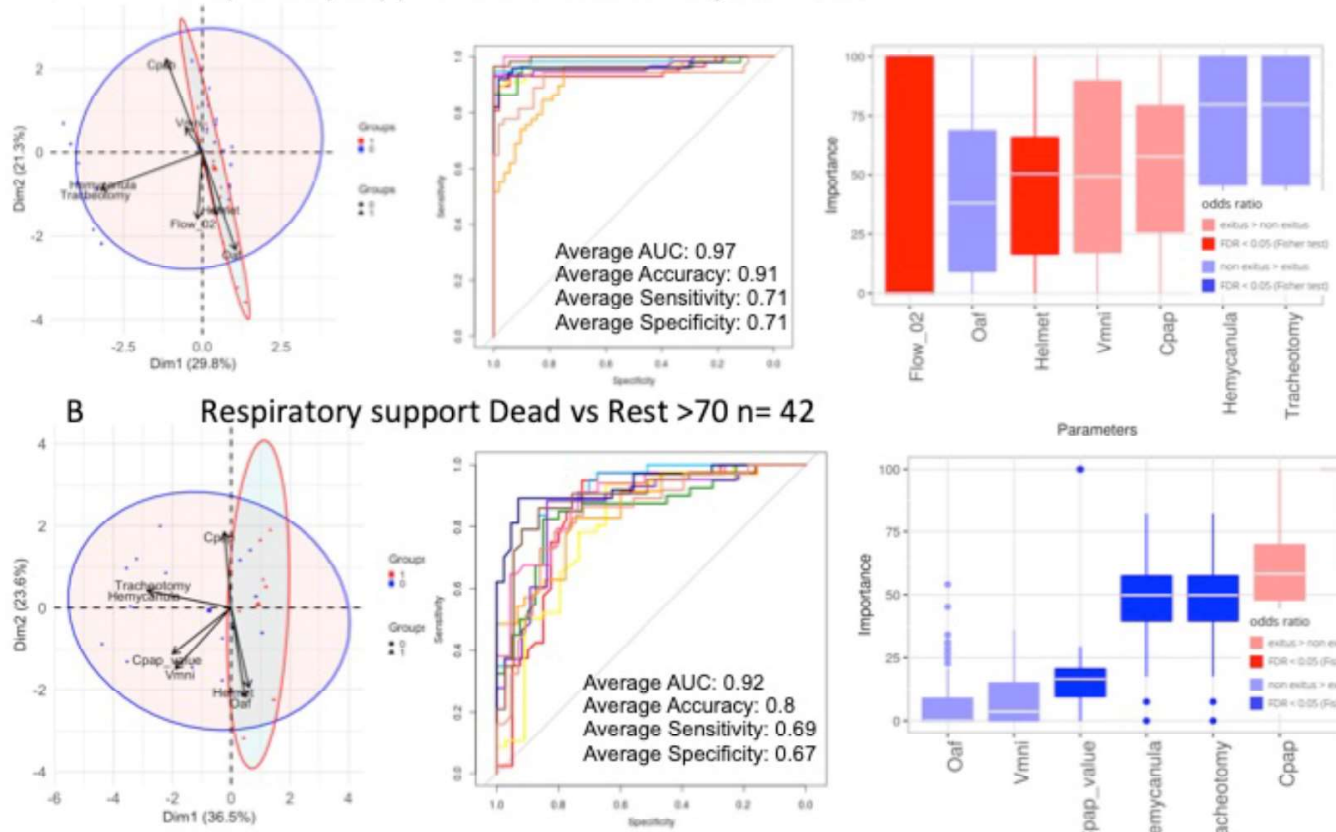

Red $\rightarrow$ ratio higher in exitus

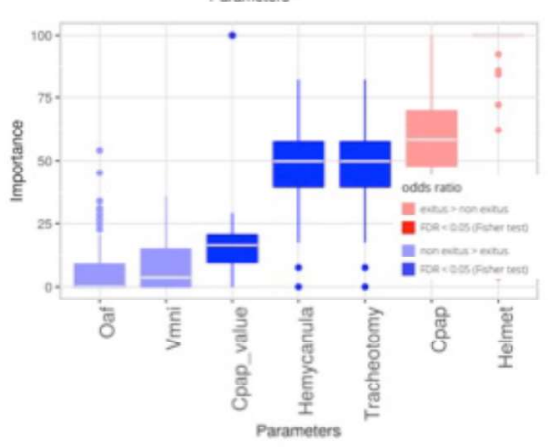

Blue $\rightarrow$ ratio higher in rest 


\section{DECLARATIONS}

\section{Ethics approval and consent to participate}

This survey is a retrospective study using de-identified medical record data. No patient management protocols have been altered due to the study. The study was approved by the Institutional Ethics Committee, certificate 09/20 with nº EO085-20_FJD.

\section{Availability of data and material}

The datasets analyzed during the current study are available from the corresponding author upon request.

\section{Competing interests}

The authors declare that they have no competing interests

\section{Funding}

The study has no specific funding. LF is supported by ISCIII (CA18/00017). PM has a Miguel Servet contract funded by the ISCIII (CP16/00116). 


\section{References}

1 Cinesi Gómez C, Peñuelas Rodríguez Ó, Luján Torné M, Egea Santaolalla C, Masa Jiménez JF, García Fernández $J$ et al. Clinical Consensus Recommendations Regarding Non-Invasive Respiratory Support in the Adult Patient with Acute Respiratory Failure Secondary to SARS-CoV-2 infection. Recomendaciones de consenso respecto al soporte respiratorio no invasivo en el paciente adulto con insuficiencia respiratoria aguda secundaria a infección por SARSCoV-2 . Arch Bronconeumol. 2020 Jul;56 Suppl 2:11-18. Doi: 10.1016/j.arbres.2020.03.005.

2 SB Heili-Frades, E. L'Her, F. Lellouche. Oxygen therapy. New toxicity data, new recommendations and innovative solutions: automated titration systems and weaning from oxygen therapy. Rev Patol Respir. 2020; 23 (1): 15-23

3 Bendjelid K, Giraud R, Treating hypoxemic patients with SARS- VOC-2 pneumonia: Back to applied physiology. Anesthesia Critical Care and Pain Medicine (2020), Doi: https://doi.org/10.1016/j.accpm.2020.04.0039

4 Elkattawy S, Noori M. A case of improved oxygenation in SARS-CoV-2 positive patient on nasal cannula undergoing prone positioning. Respir Med Case Rep. 2020; 101070. Doi: 10.1016 / j.rmcr.2020.101070

5 Hong-Liang Li, Lu Chen, Laurent Brochard J. Protecting lungs during spontaneous breathing: what can we do? Thorac Dis. 2017 Sep; 9 (9): 2777-2781. Doi: 10.21037 / jtd.2017.08.25.

6 Julia Herrero Huertas, Francisco Laso Del Hierro, Fernando Peláez Castro, Cristina Plaza Moreno, Ana Ampuero López, María Del Pilar Carballosa de Miguel et al. The Importance of Highly Specific Management in Prolonged Weaning. Importancia del manejo especializado en el destete prolongado. Arch Bronconeumol. 2019;55(8):443-444. Doi:10.1016/j.arbres.2019.02.009

7 Heili-Frades S, Carballosa de Miguel MDP, Naya Prieto A, Galdeano Lozano M, Mate García X, Mahillo Fernández I et al. Cost and Mortality Analysis of an Intermediate Respiratory Care Unit. Is It Really Efficient and Safe?. Análisis de costes y mortalidad de una unidad de cuidados intermedios respiratorios. ¿Es realmente eficiente y segura?. Arch Bronconeumol. 2019;55(12):634-641. Doi:10.1016/j.arbres.2019.06.008

8 Sarah Heili-Frades, Pablo Minguez, Ignacio Mahillo Fernández, Luis Jiménez Hiscock, Arnoldo Santos, Daniel Heili Frades et al. Patient Management Assisted by a Neural Network Reduces Mortality in an Intermediate Care Unit. Arch Bronconeumol. 2020;S0300-2896(19)30594-0. Doi:10.1016/j.arbres.2019.11.019

${ }^{9}$ Conti P, Younes A. Coronavirus COV-19/SARS-CoV-2 affects women less than men: clinical response to viral infection J Biol Regul Homeost Agents. 2020;34(2):10.23812/Editorial-Conti-3. Doi:10.23812/Editorial-Conti-3

10 Yang J, Zheng Y, Gou X, Pu K, Chen Z, Guo Q et al. Prevalence of comorbidities and its effects in patients infected with SARS-CoV-2: a systematic review and meta-analysis. Int J Infect Dis, 2020;94:91-95. Doi:10.1016/j.jijid.2020.03.017

11 Wei-Jie Guan, Wen-Hua Liang, Yi Zhao, Heng-Rui Liang, Zi-Sheng Chen, Yi-Min Li et al. Comorbidity and its impact on 1590 patients with COVID-19 in China: a nationwide analysis. Eur Respir J. 2020;55(5):2000547. Published 2020 May 14. Doi:10.1183/13993003.00547-2020

12 Safiya Richardson, Jamie S Hirsch, Mangala Narasimhan, James M Crawford, Thomas McGinn, Karina W Davidson et al. Presenting Characteristics, Comorbidities, and Outcomes Among 5700 Patients Hospitalized With COVID-19 in the New York City Area. JAMA. 2020;323(20):2052-2059. Doi:10.1001/jama.2020.6775

13 Fei Zhou, Ting Yu, Ronghui Du, Guohui Fan, Ying Liu, Zhibo Liu et al. Clinical course and risk factors for mortality of adult inpatients with COVID-19 in Wuhan, China: a retrospective cohort study. Lancet. 2020;395(10229):1054-1062. Doi:10.1016/S0140-6736(20)30566-3 
${ }^{14}$ Sarah Heili-Frades, Pablo Minguez, Ignacio Mahillo-Fernandez, Tomas Prieto-Rumeau, Antonio Herrero

Gonzalez, Lorena de la Fuente et al. COVID-19 Outcomes in 4712 consecutively confirmed SARS-CoV2 cases in the city of Madrid. medRxiv 2020.05.22.20109850; Doi: https://doi.org/10.1101/2020.05.22.20109850

15 Georgiev, Tsvetoslav. "Coronavirus disease 2019 (COVID-19) and anti-rheumatic drugs." Rheumatology international vol. 40,5 (2020): 825-826. Doi:10.1007/s00296-020-04570-z

16 Nicastri E, Petrosillo N, Ippolito G, D'Offizi G, Marchioni L, Bartoli TA, et al. National Institute for the Infectious Diseases "L. Spallanzani" IRCCS. Recommendations for COVID-19 clinical management. Infect Dis Rep. 2020 Doi: 10.4081/idr.2020.8543.

17 Julie Helms, Charles Tacquard, François Severac, Ian Leonard-Lorant, Mickaël Ohana, Xavier Delabranche et al. High risk of thrombosis in patients with severe SARS-CoV-2 infection: a multicenter prospective cohort study. Intensive Care Med. 2020;1-10. Doi:10.1007/s00134-020-06062-x

18 Bikdeli B, Madhavan MV, Jimenez D, Chuich T, Dreyfus I, Driggin E et al. COVID-19 and Thrombotic or Thromboembolic Disease: Implications for Prevention, Antithrombotic Therapy, and Follow-up. J Am Coll Cardiol. 2020;S0735-1097(20)35008-7. Doi:10.1016/j.jacc.2020.04.031

19 David Vivas, Vanessa Roldán, Maria Asunción Esteve-Pastor, Inmaculada Roldán, Antonio Tello-Montoliu, Juan Miguel Ruiz-Nodar et al. Recommendations on antithrombotic treatment during the COVID-19 pandemic. Position statement of the Working Group on Cardiovascular Thrombosis of the Spanish Society of Cardiology. Rev Esp Cardiol. 2020; Doi:10.1016/j.recesp.2020.04.006

${ }^{20}$ Horby P, Lim WS, Emberson JR, Mafham M, Bell JL, Linsell L et al. Dexamethasone in Hospitalized Patients with Covid-19 - Preliminary Report. The RECOVERY Collaborative Group.N Engl J Med. 2020 Jul 17. Doi: 10.1056/NEJMoa2021436.

21 Mehta P, McAuley DF, Brown M, Sanchez E, Tattersall RS, Manson JJ. COVID-19: consider cytokine storm syndromes and immunosuppression. Lancet. 2020 Doi: 10.1016/S0140-6736(20)30628-0.

22 WHO Clinical management of severe acute respiratory infection when novel coronavirus ( $\mathrm{nCoV}$ ) infection is suspected. Jan 28, 2020. https://www.who.int/publications-detail/clinical-management-of-severe-acute-respiratoryinfection-when-novelcoronavirus-(ncov)-infection-is-suspected

${ }^{23}$ Zhou W, Liu Y, Tian D, Wang C, Wang S, Cheng J, et al. Potential benefits of precise corticosteroids therapy for severe 2019-nCoV pneumonia. Signal Transduct Target Ther. 2020 Feb 21;5(1):18. Doi: 10.1038/s41392-020-01279.

24 Zhang C, Wu Z, Li JW, Zhao H, Wang GQ. The cytokine release syndrome (CRS) of severe COVID-19 and Interleukin-6 receptor (IL-6R) antagonist Tocilizumab may be the key to reduce the mortality. Int J Antimicrob Agents. 2020 Mar 29:105954. Doi: 10.1016/j.jjantimicag.2020.105954.

25 Poe FL, Corn J. N-Acetylcysteine: A potential therapeutic agent for SARS-CoV-2 .Med Hypotheses. 2020;143:109862. Doi:10.1016/j.mehy.2020.109862

${ }^{26}$ Sanchez-Pernaute O, Romero-Bueno FI, Selva-O'Callaghan A. Why choose Cyclosporine A as first-line therapy in COVID-19 pneumonia. Reumatol Clin 2020 (in press). DOI: 10.1016/j.reuma.2020.03.001

27 The SARS-CoV2 study group of HU Fundación Jimenez Díaz is currently conducting a clinical trial to test efficacy and safety of CsA as add-on therapy with standard of care in a 1:1 randomization with severity stratification (EudraCT 2020-002621-11; ClinicalTrials.gov ID: NCT04392531)

28 Patel BK, Wolfe KS, Pohlman AS, Hall JB, Kress JP. Effect of Noninvasive Ventilation Delivered by Helmet vs Face Mask on the Rate of Endotracheal Intubation in Patients With Acute Respiratory Distress Syndrome: A Randomized Clinical Trial. JAMA. 2016 Jun 14;315(22):2435-41. Doi: 10.1001/jama.2016.6338. 
${ }^{29}$ Hui DS, Chow BK, Lo T, Ng SS, Ko FW, Gin T, et al. Exhaled air dispersión during noninvasive ventilation via helmets and a total facemask. Chest. 2015 May;147(5):1336-1343. DOI: 10.1378/chest.14-1934

${ }^{30}$ Antonelli M, Conti G, Pelosi P, Gregoretti C, Pennisi MA, Costa R, et al. New treatment of acute hypoxemic respiratory failure: noninvasive pressure support ventilation delivered by helmet--a pilot controlled trial. Crit Care Med. 2002 Mar;30(3):602-8. DOl: 10.1097/00003246-200203000-00019

${ }^{31}$ Antonelli M, Pennisi MA, Pelosi P, Gregoretti C, Squadrone V, Rocco M, et al. Noninvasive positive pressure ventilation using a helmet in patients with acute exacerbation of chronic obstructive pulmonary disease: a feasibility study. Anesthesiology. 2004 Jan;100(1):16-24. Doi: 10.1097/00000542-200401000-00007.

32 Rocco M, Dell'Utri D, Morelli A, Spadetta G, Conti G, Antonelli M, et al. Noninvasive ventilation by helmet or face mask in immunocompromised patients: a case-control study. Chest. 2004 Nov;126(5):1508-15. Doi: 10.1001/jama.2016.6338.

${ }^{33}$ Rochwerg B, Granton D, Wang DX, Helviz Y, Einav S, Frat JP, et al. High flow nasaLcannula compared with conventional oxygen therapy for acute hypoxemic respiratory failure: a systematic review and metaranalysis. Intensive Care Med 2019;45:563-72. Doi: 10.1001/jama.2016.6338.

${ }^{34}$ Coudroy R, Frat JP, Ehrmann S, Pène F, Terzi N, Decavèle M, et al. High-flow nasal oxygen therapy alone or with non-invasive ventilation in immunocompromised patients admitted to ICU for acute hypoxemic respiratory failure: The randomised multicentre controlled FLORALI-IM protocol. BMJ Open 2019;9. Doi: 10.1136/bmjopen-2019-029798.

${ }^{35}$ Brochard L, Slutsky A, Pesenti A. Mechanical ventilation to minimize progression of lung injury in acute respiratory failure. Am J Respir Crit Care Med 2017;195:438-42. Doi: 10.1164/rccm.201605-1081CP.

${ }^{36}$ Arulkumaran N, Brealey D, Howell D, Singer M. Use of non-invasive ventilation for patients with COVID-19: a cause for concern?. Lancet Respir Med. 2020;8(6):e45. Doi:10.1016/S2213-2600(20)30181-8

${ }^{37}$ WHO. Clinical management of severe acute respiratory infection when Novel coronavirus (2019-nCoV) infection is suspected: Interim Guidance. WHO/nCoV/Clinical/2020.4 March 132020.

38 Harari SA, Vitacca M, Blasi F, Centanni S, Santus PA, Tarsia P. Managing the Respiratory care of patients with COVID-19 . http://www.aiponet.it: Italian Thoracic Society - Associazione Italiana Pneumologi Ospedalieri - Societa Italiana Di Pneumologia;2020.

39 Respiratory care committee of Chinese Thoracic S. Expert consensus on preventing nosocomial transmission during respiratory care for critically ill patients infected by 2019 novel coronavirus pneumonia. Zhonghua Jie $\mathrm{He} \mathrm{He}$ Hu Xi Za Zhi. 2020 Feb 20;17(0):E020. Doi: 10.3760/cma.j.issn.1001-0939.2020.0020.

40 Lila Bouadma, Francois-Xavier Lescure, Jean-Christophe Lucet, Yazdan Yazdanpanah, Jean-Francois Timsit. Severe SARS-CoV-2 infections: practical considerations and management strategy for intensivists. Intensive Care Medicine. 2020;46 (4):579-582. DOI: 10.1007/s00134-020-05967-x 
$41 \quad$ Mathilde Oranger, Jésus Gonzalez-Bermejo, Philippine Dacosta-Noble, Claudia Llontop, Antoine Guerder, Valery Trosini-Desert et al. Continuous positive airway pressure to avoid intubation in SARS-CoV-2 pneumonia: a twoperiod retrospective case-control study. Eur Respir J. 2020 May 19;2001692. Doi: 10.1183/13993003.01692-2020.

42 Hua J, Qian C, Luo Z, Li Q, Wang F. Invasive mechanical ventilation in COVID-19 patient management: the experience with 469 patients in Wuhan. Crit Care. 2020;24(1):348. Published 2020 Jun 16. Doi:10.1186/s13054-02003044-9

43 Frat JP, Thille AW, Mercat A, Girault C, Ragot S, Perbet S, et al. High-flow oxygen through nasal cannula in acute hypoxemic respiratory failure. N Engl J Med 2015;372:2185-96. Doi: 10.1056/NEJMoa1503326. Epub 2015 May 17.

44 Thompson BT, Wheeler A.Ventilation with lower tidal volumes as compared with traditional tidal volumes for acute lung injury and the acute respiratory distress syndrome. N Engl J Med. 2000 May 4;342(18):1301-8. Doi: 10.1056/NEJM200005043421801.

45 Yoshida T, Amato MBP, Kavanagh BP, Fujino Y.Impact of spontaneous breathing during mechanical ventilation in acute respiratory distress syndrome. Curr Opin Crit Care. 2019 Apr;25(2):192-198. Doi: 10.1097/MCC.0000000000000597.

46 Yoshida T, Grieco DL, Brochard L, Fujino Y. Patient self-inflicted lung injury and positive end-expiratory pressure for safe spontaneous breathing. Curr Opin Crit Care. 2020;26(1):59-65. Doi:10.1097/MCC.0000000000000691

47 Gattinoni L, Chiumello D, Rossi S. COVID-19 pneumonia: ARDS or not?. Version 2. Crit Care. 2020 Apr 16;24(1):154. Doi: 10.1186/s13054-020-02880-z.

${ }^{48}$ S. B. Heili Frades, G. Peces Barba Romero, M. Villar, S. Pelicano, M. J. Checa Venegas, R. Gutiérrez Fonseca, et al. Ventilación mecánica y traqueotomía. Protocolo de destete de ventilación mecánica y decanulación de la Unidad de Cuidados Respiratorios Intermedios de la Fundación Jiménez Díaz. Revista de Patología Respiratoria. Vol. 14. Núm. 3.Julio 2011. páginas 67-107.

49 McGrath BA, Brenner MJ, Warrillow SJ, Pandian V, Asit A, Cameron T et al. Tracheostomy in the COVID-19 era: global and multidisciplinary guidance. Lancet Respir Med. 2020 Jul;8(7):717-725. Doi: 10.1016/S22132600(20)30230-7.

50 Kotfis K, Williams Roberson S, Wilson JE, Dabrowski W, Pun BT, Ely EW. COVID-19: ICU delirium management during SARS-CoV-2 pandemic. Version 2. Crit Care. 2020 Apr 28;24(1):176. Doi: 10.1186/s13054-020-02882-X.

51 Piccin O, Albertini R, Caliceti U, Cavicchi O, Cioccoloni E, Demattè M et al. Early experience in tracheostomy and tracheostomy tube management in COVID-19 patients. Am J Otolaryngol. Jul-Aug 2020;41(4):102535. Doi: 10.1016/j.amjoto.2020.102535. 
Figures

A

\begin{tabular}{|c|c|c|}
\hline IRCU PATIENTS & N 274 & $\%$ \\
\hline Ircu Admission With Outcome Alive & 144 & 52,5 \\
\hline Ircu Admission With Outcome Dead (Ircu failure) & 34 & 12,4 \\
\hline Ircu Success (Survivals And Achieved Icu Transfer) & 240 & 87,59 \\
\hline Transfer To Icu Alive & 96 & 35 \\
\hline Delaved Dead In Icu (Delaved Ircu Failure) & 11 & $6 \%$ \\
\hline
\end{tabular}

C

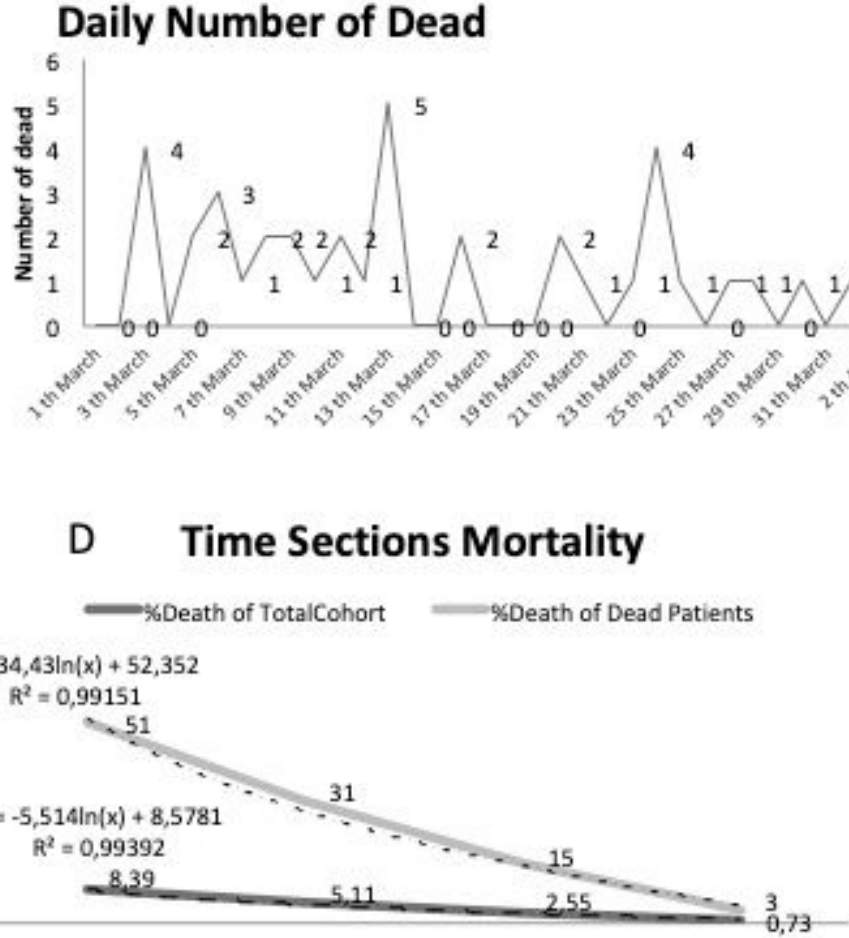

1th to 15 th March 16th ti 31th March 1th to 15 th April 16th April to 5th May
Mortality and age range

$y=2,7372 x^{3}-6,3139 x+20,255 \longleftarrow \mathbf{N}_{\mathrm{N}} \leftarrow \%$ DEAD $\longrightarrow y=7,4596 \mathrm{x}^{2}-19,669 \mathrm{x}+30,281$ $R^{2}=0,9853 \quad-N \%+\frac{R}{2}=0,9838$

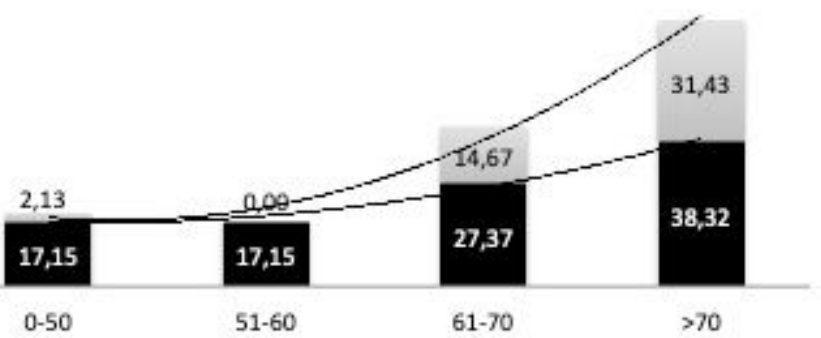

E IRCU Time Evolution on March and April 2020

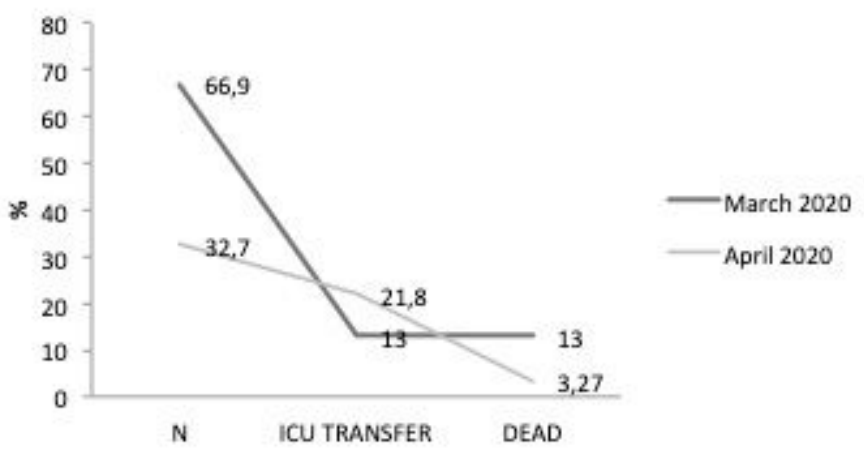

Figure 1

See manuscript file for figure legend. 
A Dead vs Rest All ages $n=266$
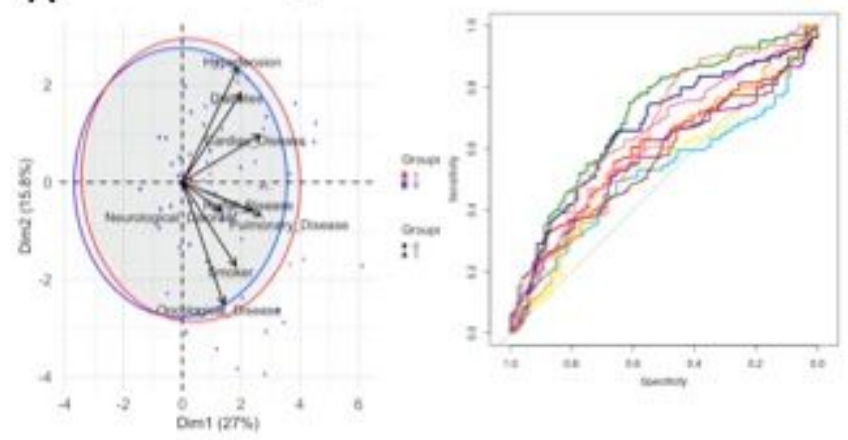

B Dead vs Rest $50-70$ years $n=123$
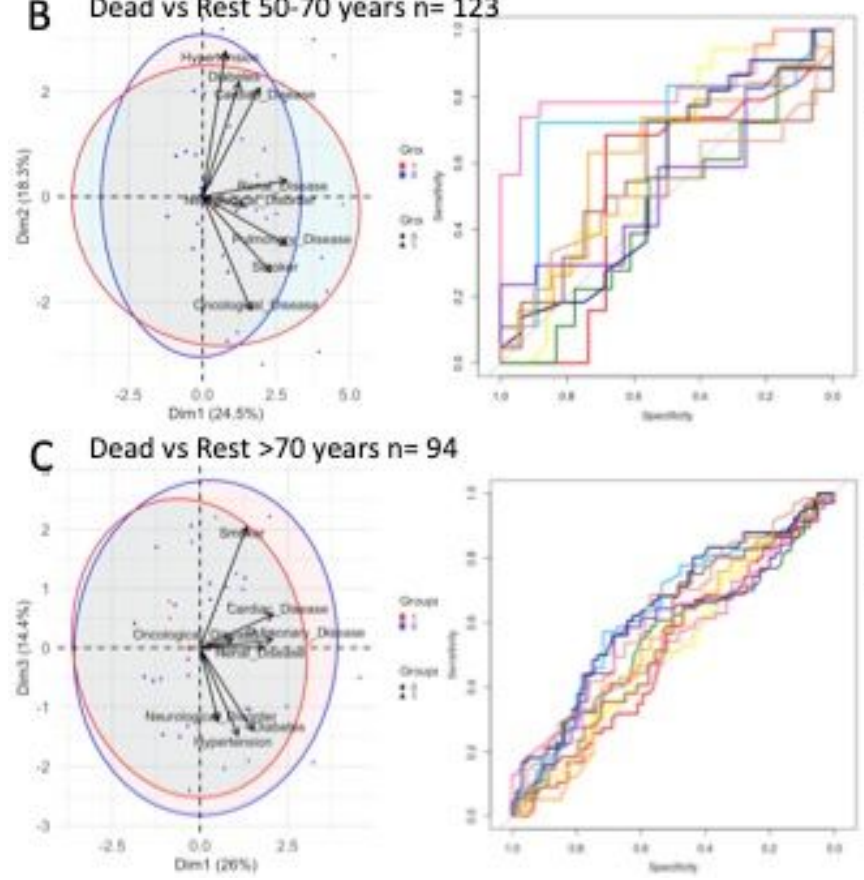

\section{$n=94$}

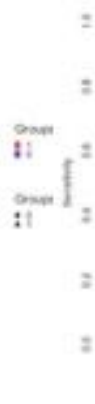

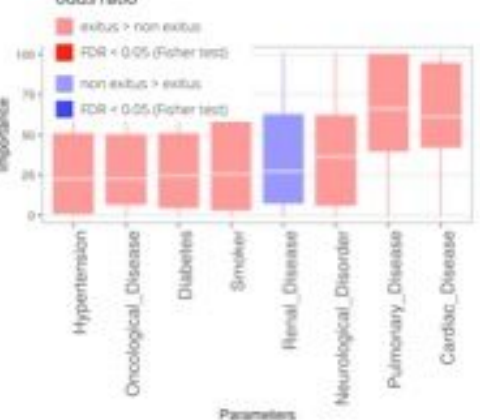

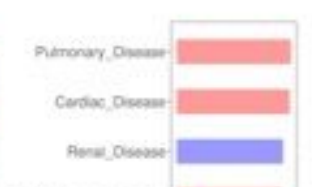

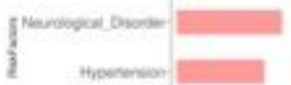

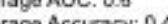
Awerage Accuracy: 0.42 Average Sensitivity: 0.53

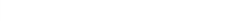

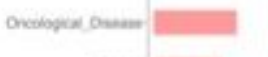

Sutein |

odds ratio

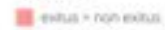

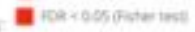

\begin{tabular}{|c|c|c|c|c|c|c|}
\hline & \\
\hline
\end{tabular}

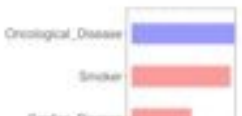

Average AUC: 0.81 Average Aocuracy: 0.56

Average Sensitivity: 0.61 Average Specificity: 0.62

Figure 2

See manuscript file for figure legend. 


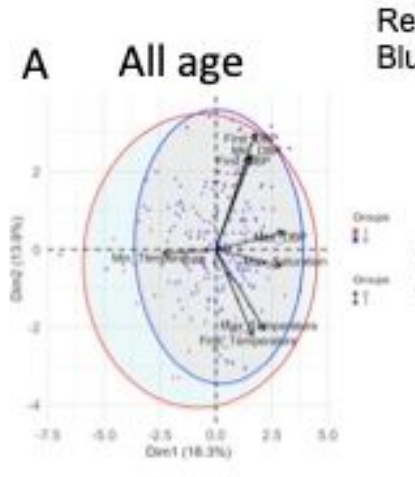

Red $\rightarrow$ ratio higher in exitus

Blue $\rightarrow$ ratio higher in ICU

\section{B $\quad 50-70$ years}
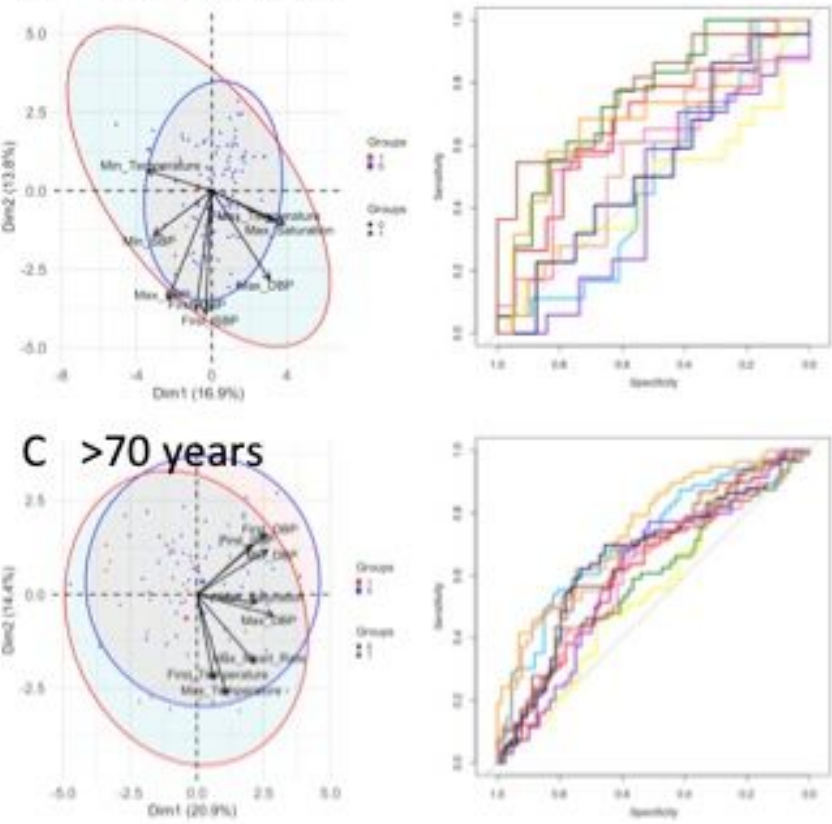

odds ratio

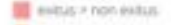

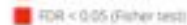

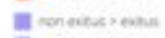
है

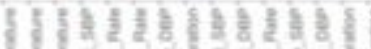

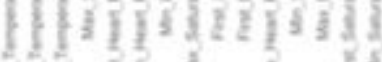

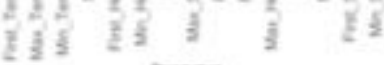

\section{odds ruta}

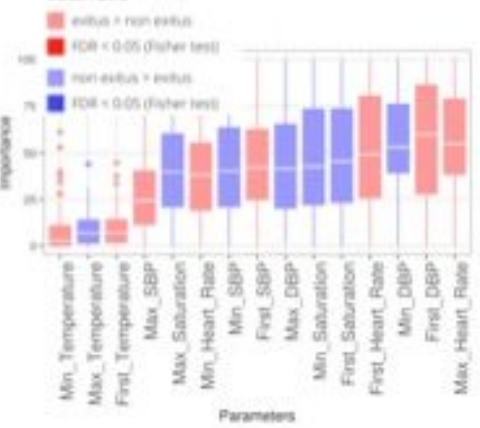

odds ratio

atil mons noc nuty

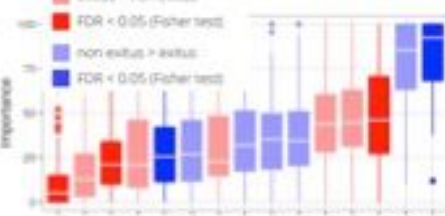

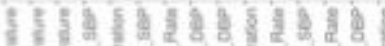

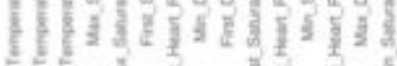

दो है है है है
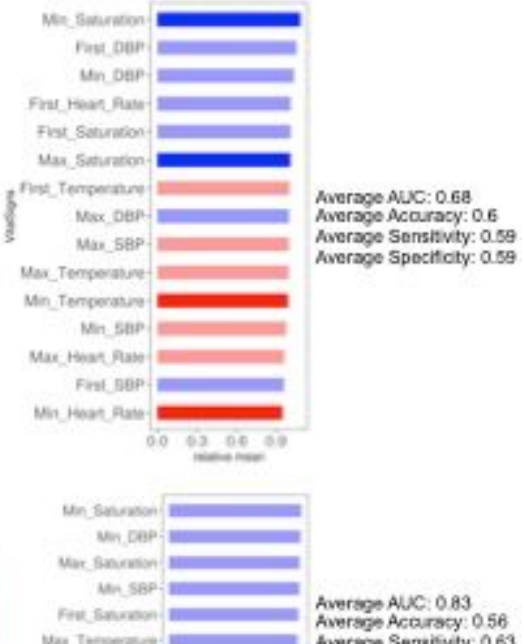

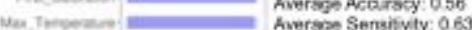

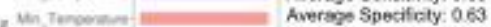

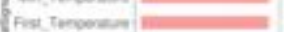

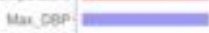
Ans Dep:

Pove Jean Rath

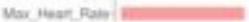
Anst sep:

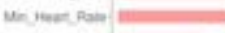

Man sap tera

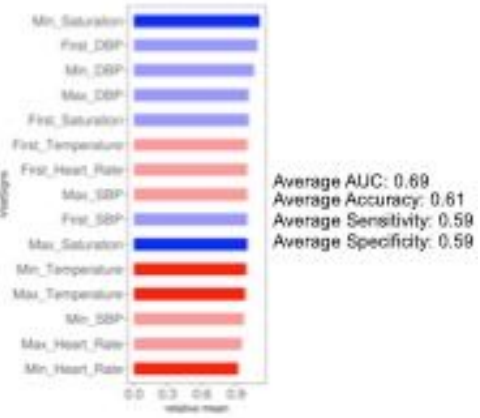

Figure 3

See manuscript file for figure legend. 

A $\quad 50-70$ years $n=122$
Red $\rightarrow$ ratio higher in exitus
Blue $\rightarrow$ ratio higher in ICU

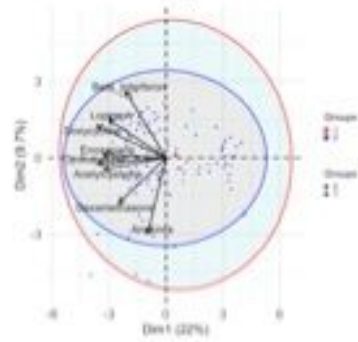

\section{B $>70$ years $\mathrm{n}=94$}
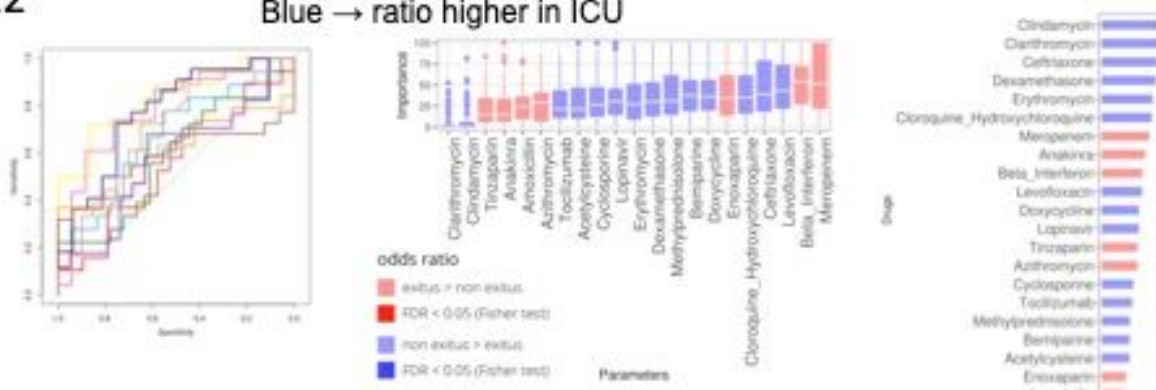

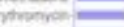

Conoume Hoverphosoine $=$ nown $=$

Average AUC:0.

Average Accursoy: 0.41

Average Sensitivity. 0.62

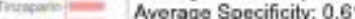

odds ravio

acos coss oinert

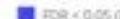

mach

ronsente

tronesum $=$

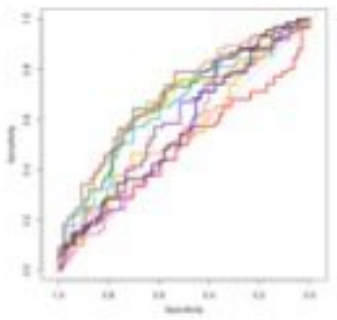

है
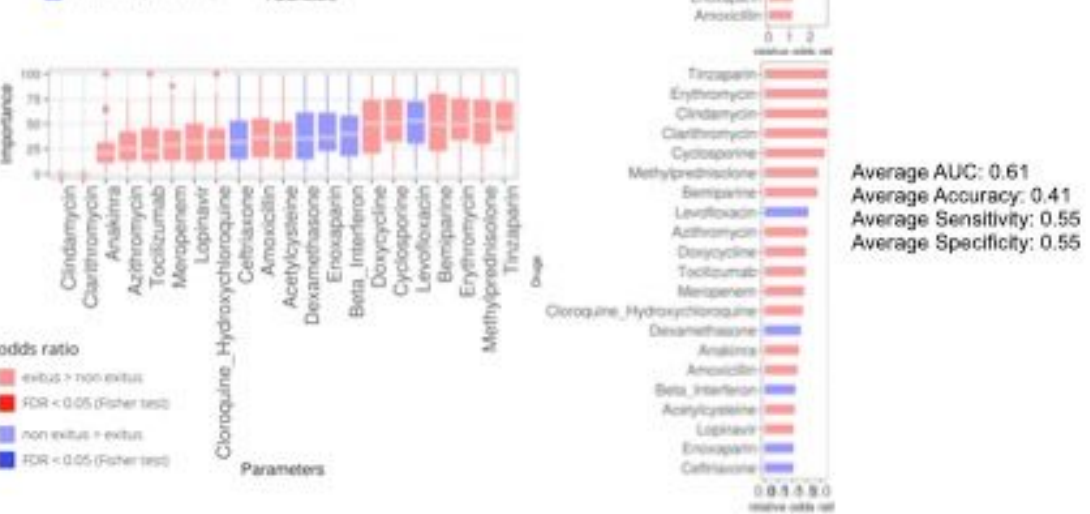

C All Ages (Most Severe.ICU transfer and Dead $n=130$ )
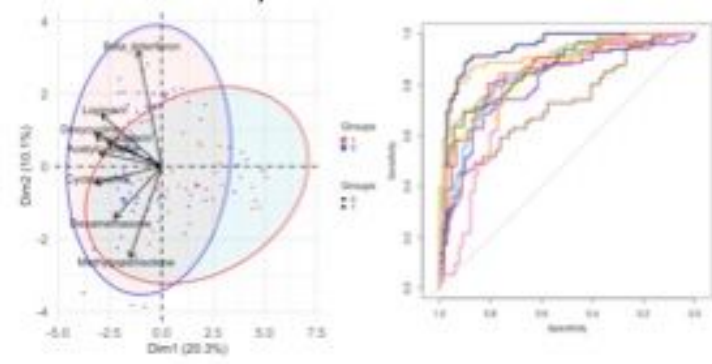

$$
\text { है }
$$
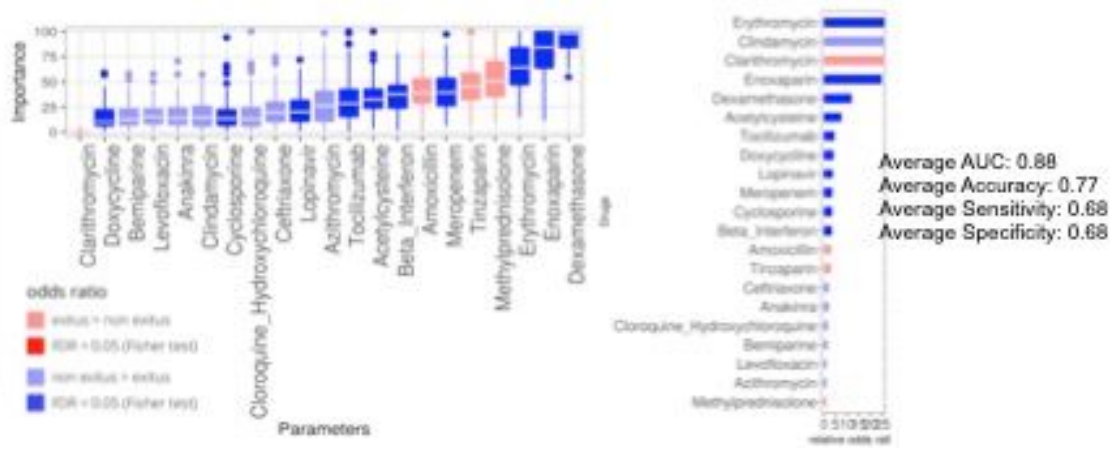

Figure 4

See manuscript file for figure legend. 


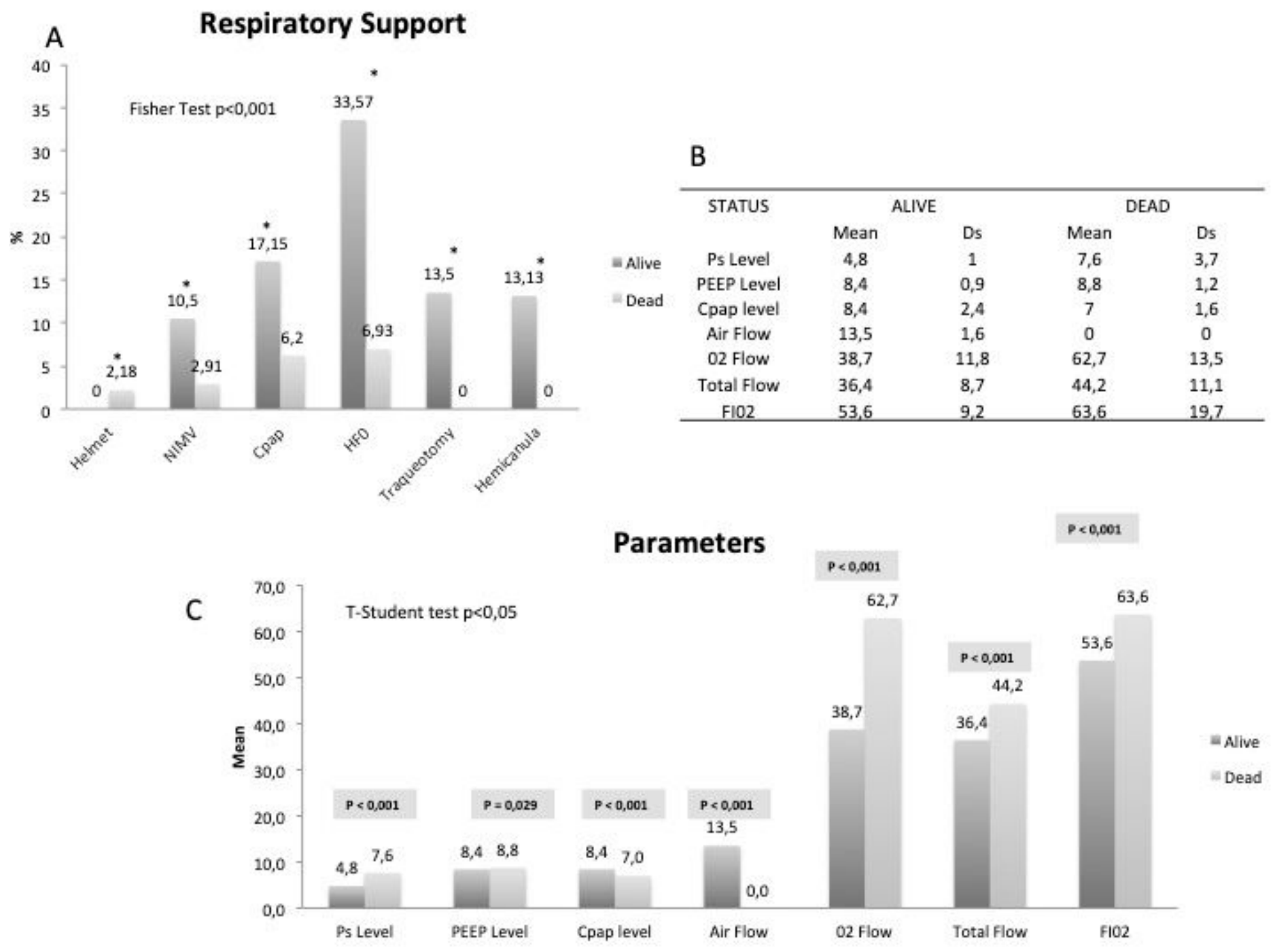

Figure 5

See manuscript file for figure legend. 

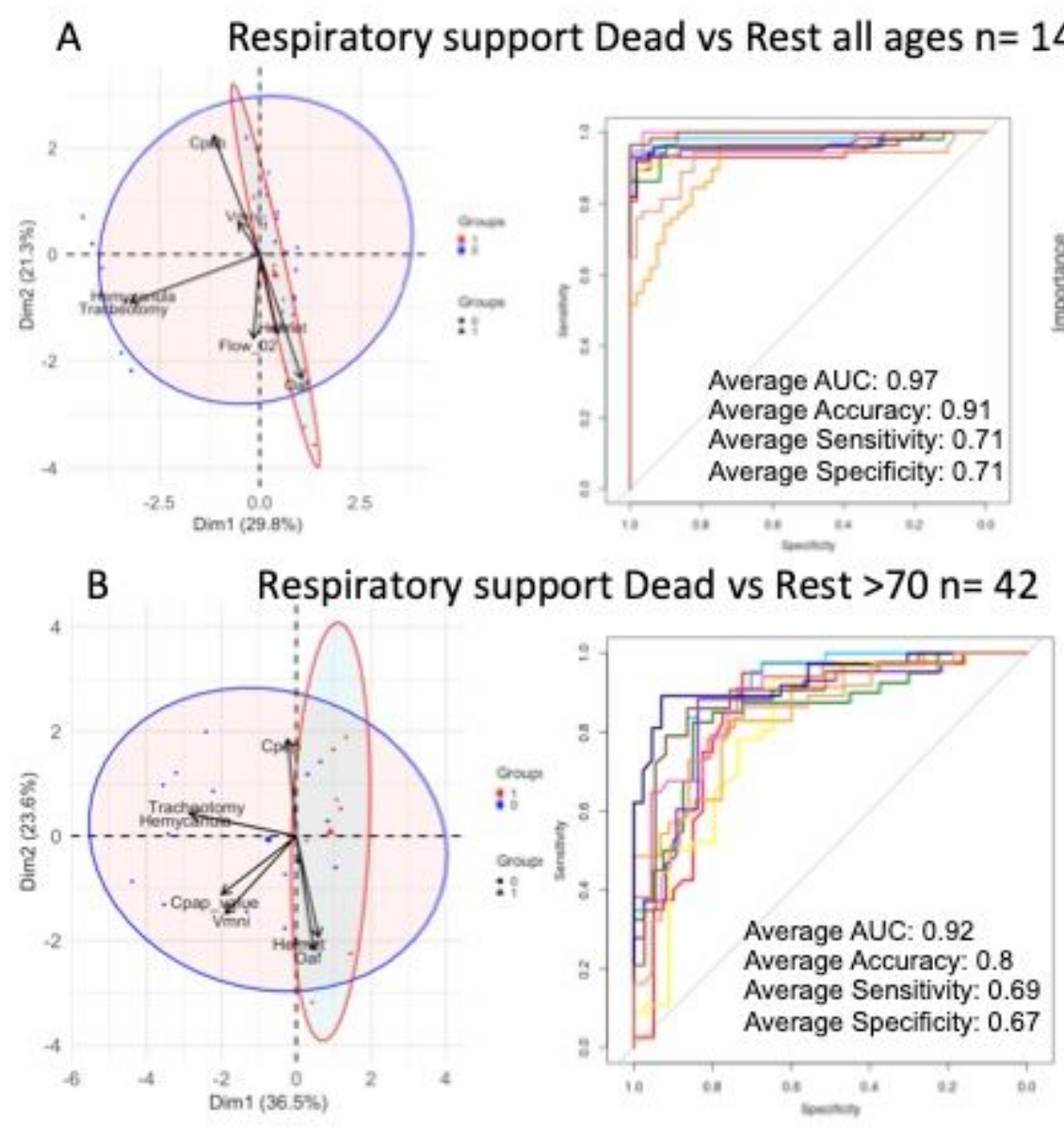

Red $\rightarrow$ ratio higher in exitus
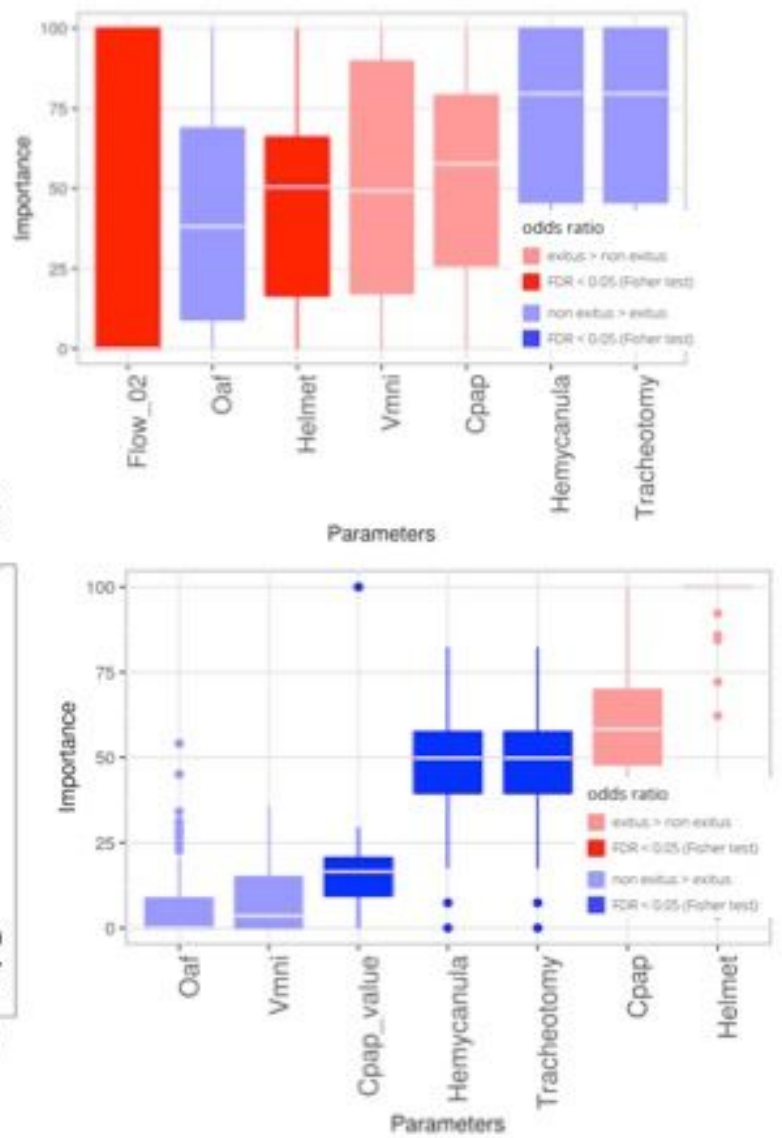

Blue $\rightarrow$ ratio higher in rest

Figure 6

See manuscript file for figure legend.

\section{Supplementary Files}

This is a list of supplementary files associated with this preprint. Click to download.

- SupplementaryFigure2.jpg

- SupplementaryFigure2.jpg

- SupplementaryFigure1.jpg

- SupplementaryFigure1.jpg

- SupplementaryFigure3.jpg

- SupplementaryFigure3.jpg

- SupplementaryFigure4.jpg

- SupplementaryFigure4.jpg 
- SupplementaryFigure5.jpg

- SupplementaryFigure5.jpg

- SupplementaryFigure6.jpg

- SupplementaryFigure6.jpg

- SupplementaryFigure7.jpg

- SupplementaryFigure7.jpg

- SupplementaryFigure8.jpg

- SupplementaryFigure8.jpg

- SupplementaryTable1.pdf

- SupplementaryTable1.pdf 